\title{
The demand for Swiss banknotes: some new evidence
}

\author{
Katrin Assenmacher ${ }^{1}$, Franz Seitz ${ }^{2}$ and Jörn Tenhofen ${ }^{3 *}$ (i)
}

\begin{abstract}
Knowing the part of currency in circulation that is used for transactions is important information for a central bank. For several countries, the share of banknotes that is hoarded or circulates abroad is sizeable, which may be particularly relevant for large-denomination banknotes. We analyze the demand for Swiss banknotes over a period starting in 1950 to 2017 and use different methods to derive the evolution of the amount that is hoarded. Our findings indicate a sizeable amount of hoarding, in particular for large denominations. The hoarding shares increased around the break-up of the Bretton Woods system, were comparatively low in the mid-1990s, and have increased significantly since the turn of the millennium and the recent financial and economic crises.
\end{abstract}

Keywords: Currency in circulation, Cash, Demand for banknotes, Hoarding of banknotes, Banknotes held by non-residents

\section{JEL Classification: E41; E52; E58}

\section{Introduction}

In many economies, demand for cash is growing despite an increasing share of electronic payments driven by continuous innovations in payment technology. ${ }^{1}$ In Switzerland, similar to some other countries, the increase in the demand for banknotes has even accelerated since the global financial crisis (Assenmacher et al. 2018, see Fig. 4). One factor contributing to this increase could be low nominal interest rates, which reduce the opportunity cost of holding banknotes, e.g., as a store of value. Other factors might also be important, such as distrust in the banking system, and are likely complemented by other forces that have been present for longer, such as a desire for privacy or anonymity in transactions and the use of banknotes abroad.

Knowing the share of cash that is used for transactions in the domestic economy is of interest for central banks given that shifts in the hoarding or foreign share may complicate the interpretation of movements in the domestic monetary base or narrow monetary aggregates. Aksoy and

\footnotetext{
*Correspondence: joern.tenhofen@snb.ch

${ }^{3}$ Swiss National Bank, Börsenstrasse 15,8022 Zürich, Switzerland

Full list of author information is available at the end of the article

${ }^{1}$ For international evidence, see Bagnall et al. (2016), Jobst and Stix (2017), or Bech et al. (2018); for survey evidence on Switzerland, see Swiss National Bank (2018).
}

Piskorski (2006), for instance, show that the link between money and inflation or output in the United States (US) becomes stronger if domestic monetary aggregates are corrected for foreign holdings of US dollars. Central banks also have an interest in monitoring cash developments because of their role in operating the payment system. If banknotes are predominantly demanded for hoarding purposes, banknotes in circulation might show an upward trend but cash actually used in transactions may even decline. $^{2}$ Financial innovation and network effects can lead to rapid changes in the dominant means of payment in an economy. The Swedish Riksbank, for instance, which has seen the demand for cash decline strongly since 2008 and expects half of Swedish retailers to stop accepting cash by 2025 , is currently investigating options for a digital alternative to cash (see Sveriges Riksbank 2018). Finally, hoarding demand for cash often reflects mistrust in the banking system and surges when there is turbulence in financial markets, creating both logistical challenges for the central bank and financial stability issues for banks. Analyzing the evolution of hoarding demand around these events can help in predicting and preparing for potential consequences from such behavior. Moreover, in light of the Swiss National Bank's (SNB) negative interest rate

\footnotetext{
$\overline{2}$ Bech et al. (2018) document the rising demand for cash in many economies that goes along with increased use of electronic payments.
}

Springer Open

(c) The Author(s). 2019 Open Access This article is distributed under the terms of the Creative Commons Attribution 4.0 International License (http://creativecommons.org/licenses/by/4.0/), which permits unrestricted use, distribution, and reproduction in any medium, provided you give appropriate credit to the original author(s) and the source, provide a link to the Creative Commons license, and indicate if changes were made. 
since 2015, the opportunity costs for holding Swiss franc banknotes are at an unprecedented low level, which might fuel hoarding demand further. ${ }^{3}$

While hoarding and non-resident demand is well documented for the US and the euro area, ${ }^{4}$ evidence for Switzerland is scarce. The most comprehensive study by Andrist (1997) is more than 20 years old and therefore neither covers the financial crisis nor the phase of low or even negative interest rates. Moreover, Switzerland is of particular interest as the CHF 1000 banknote is one of the largest denominations issued worldwide and accounted for more than $60 \%$ of the value of Swiss banknotes in circulation in 2018, compared to approximately $25 \%$ at the beginning of the 1970s (see the lower panel of Fig. 11 in the Appendix). ${ }^{5}$ Figures 10 and 11 in the Appendix illustrate the evolution of total banknotes and of the different denominations since the beginning of the 1950s, both in terms of value and number. The nominal value of total banknotes increased steadily during this time period, driven mostly by the CHF 1000 note (see the upper panel of Fig. 11 in the Appendix), with a drastic rise in the last 10 years. Assenmacher et al. (2018, Section 2) present detailed stylized facts on the demand for Swiss banknotes from 1907 to 2015.

In this paper, we use different methods to estimate the time-varying share of Swiss banknotes-for both individual denominations and the total-that is hoarded over the period from 1950 to 2017. Our definition of hoarding comprises all possible uses of cash apart from domestic transactions, i.e., domestic and foreign hoarding of banknotes as well as potential Swiss franc transactions abroad. ${ }^{6}$ Almost all approaches used to estimate hoarding demand rely on a comparison with a benchmark value or series that by assumption is determined by the same factors as the series of interest but is not characterized by hoarding. ${ }^{7}$ The choice of this benchmark can naturally have a large influence on the results, while it is difficult to validate the assumptions underlying its choice. It is

\footnotetext{
${ }^{3}$ The availability of high-denomination banknotes is typically mentioned as a barrier to implementing highly negative interest rates for monetary policy reasons. For example, see Rogoff (2016).

${ }^{4}$ See, e.g., Porter (1993) or Porter and Judson (1996) for the US, Bartzsch et al. (2011a, b, 2013a, b), and Fischer et al. (2004) for the euro area.

${ }^{5}$ The US faces a similar situation with its largest banknote denomination, the USD 100 bill, accounting for approximately $80 \%$ of the total value of banknotes in circulation. However, it is only about a tenth of the value of the CHF 1000 note. By contrast, the EUR 500 banknote, which is also a relatively large denomination, only reached a peak share of approximately $30 \%$ of the total value of euro banknotes in circulation, which dropped noticeably following the European Central Bank's 2016 decision to discontinue its issuance, scheduled for the first half of 2019.

${ }^{6}$ As the Swiss franc does not seem to be used for transaction purposes in other countries (Andrist 1997), we interpret our estimates as encompassing both foreign and domestic hoarding. Our definition differs from that used in surveys; see Swiss National Bank (2018). We do not distinguish between legal and illegal purposes.

${ }^{7}$ See Fischer et al. (2004) as well as Bartzsch et al. (2011a, b) for different methods to estimate hoarding or non-resident holdings.
}

therefore advisable to assess the robustness of the estimated hoarding share by employing a range of methods and benchmarks that start from different assumptions. Our choice of methods is driven by data availability. As we lack data on banknote shipments abroad or data on the distribution of banknotes after the introduction of a new banknote series, we cannot apply methods that are based on this kind of information. The first comprehensive survey by the SNB on the distribution of cash holdings and payment habits in Switzerland was conducted only in 2017 (see Swiss National Bank 2018), which prevents us from analyzing patterns in the use of banknotes in transactions over time.

This paper is structured as follows. Section 2 estimates demand equations by denomination group (small, medium, large) starting from 1950 and investigates the elasticity of cash demand with respect to the interest rate and the exchange rate of the Swiss franc. We find that the interest rate and exchange rate elasticity tend to be lower in absolute value for the smaller denominations, which we interpret as evidence that these denominations are demanded less for hoarding purposes. Section 3 offers a simple estimate of hoarding demand based on the assumption that the growth rate of different denominations should evolve in lockstep if they are only used for transactions and that deviations from this pattern indicate hoarding demand. Section 4 exploits the fact that banknotes not used for transactions wear off more slowly and assesses the hoarding share based on the lifespan of different banknote denominations. Section 5 extends the analysis in Assenmacher et al. (2018) by applying the seasonal method to daily data and investigating the intra-weekly seasonal pattern. Section 6 summarizes and concludes.

Overall, our results indicate that a significant part of large-denomination banknotes is hoarded, although the precise point estimates differ to some extent depending on the method used. In line with the threshold of 75 US dollars used by Bech et al. (2018) to split between large and small denominations, we assume that only CHF 1000, 500, 200, and 100 banknotes are potentially affected by hoarding whereas the smaller denominations are mainly used for transactions. ${ }^{8}$ For the CHF 1000 note, we calculate a hoarding share in 2017 between 80 and $90 \%$. For the CHF 200 note, we estimate hoarding shares between 30 and $60 \%$, whereas for the CHF 100 note hoarding shares are between 10 and 20\%. Assuming that denominations below CHF 100 are not hoarded, these estimates imply

\footnotetext{
${ }^{8}$ In 2017, USD 75 corresponded to approximately CHF 74 using market exchange rates and CHF 89 with the OECD's purchasing power parity rates. For the euro area, smaller denominations also seem to be circulating abroad or are hoarded (Bartzsch and Uhl 2018; Deutsche Bundesbank 2018). As the Swiss franc is not circulating as a currency in other countries, we consider the foreign and hoarding demand for smaller denominations to be less important than for the euro.
} 
that between 55 and $70 \%$ of the value of total banknotes in circulation were actually not demanded for transaction purposes in 2017. In this context, it must be noted that the total hoarding share is dominated by hoarding of the CHF 1000 banknote, which accounts for approximately $60 \%$ of the total value of Swiss banknotes in circulation.

The different methods also paint a rather consistent picture with respect to movements over time. The hoarding shares increased around the break-up of the Bretton Woods system, were comparatively low in the mid-1990s, and have increased significantly since the turn of the millennium and the financial crisis of 2008. With respect to the timing of the most recent increase, some differences between the denominations can be seen. The hoarding share of the CHF 1000 banknote increased noticeably around the turn of the millennium whereas its increase during the recent financial crisis was less pronounced and occurred already in the early stage of the crisis. In contrast, the CHF 100 bill saw a strong increase in its hoarding share only in the later stages of the euro area crisis, whereas the CHF 200 note exhibits noticeable increases both in the financial and the euro area crises.

\section{Evidence from money demand equations}

As a first step to investigating hoarding and non-resident demand, we estimate demand equations for banknotes. This allows us to assess the importance of potential factors such as income or opportunity costs, reflected by variables such as interest rates and exchange rates, for the demand for a given denomination. We expect that the demand for smaller denominations would mainly be driven by a transactions motive for cash, whereas for larger denominations portfolio considerations-of both residents and non-residents-might be of importance as well. While transaction demand is probably better captured by inventory theoretic approaches to money demand, see Baumol (1952) and Tobin (1956), which predict an income elasticity of 0.5 , portfolio allocation approaches would imply a higher income elasticity and a significant influence of opportunity cost variables. ${ }^{9}$

We perform dynamic OLS (DOLS) single-equation cointegration regressions on annual data from 1950 to 2017 in order to estimate the parameters on the longrun relationships. ${ }^{10}$ As dependent variables, we consider

\footnotetext{
${ }^{9}$ In a meta-analysis of the income elasticity of money demand, Knell and Stix (2005) find a lower income elasticity for narrow aggregates that are more closely related to the transactions motive.

${ }^{10}$ Results using fully modified OLS are similar. As Banerjee et al. (1986) have shown, (asymptotically efficient) DOLS is superior to the two-step procedure of Engle and Granger (1987) as it avoids the small sample bias. Furthermore, this approach still yields valid results in the case of structural breaks (Campos et al. 1996). We prefer a single-equation method over a vector error correction (VECM) system that models the short-run dynamics along with the long-run coefficients as the dynamics might be unstable over time.
}

three different groups of denominations: large (CHF 1000, CHF 500, and CHF 200), medium (CHF 100 and CHF 50), and small (CHF 20, CHF 10, and CHF 5). By grouping several denominations into categories, we do not need to explicitly model substitution effects that occur inside a category, in particular when a denomination is replaced by another. In our sample, for instance, the issuance of the CHF 5 banknote was suspended in 1958 after the introduction of the CHF 10 note in 1956. Moreover, the CHF 500 banknote was withdrawn from circulation in 1997 and replaced by the CHF 200 note. $^{11}$

The dependent variable is the (log of the) value in circulation of the respective denomination group, deflated by the consumer price index (CPI). As explanatory variables, we include the $\log$ of real GDP and two measures of the opportunity cost of holding cash, namely, the 10-year government bond yield and the nominal exchange rate of the Swiss franc to the Deutschemark/euro. ${ }^{12}$ The inclusion of an exchange-rate term in cash demand studies is common to capture the influence of foreign demand (see, e.g., Bartzsch and Seitz 2016, Flannigan and Parsons 2018). Moreover, we add the log of the real value of payments by debit card and the log of the number of cashed checks to capture advances in payment technologies. ${ }^{13}$ The banknote data are from the SNB, the debit card and check data are from the BIS, and the other variables are from Historical Statistics of Switzerland Online (HSSO).

The results in Table 1 show that, first, all coefficients have the expected sign. The income elasticities are positive, while higher interest rates and more debit card or check payments reduce banknote demand. A depreciation of the Swiss franc reduces demand for Swisss banknotes. ${ }^{14}$ Second, the income elasticities for all categories of denominations are significant and differ. The elasticity is largest for the high

\footnotetext{
${ }^{11}$ In Section 3 we will show that the replacement of the CHF 500 by the CHF 200 banknote affected demand for the CHF 100 note as well; see also Kohli (1988). Our regression results remain qualitatively the same if we use only two groups of denominations and include the CHF 100 in the large and the CHF 50 bill in the small denomination group.

${ }^{12}$ We use annual data for the estimation because quarterly GDP data for Switzerland are available only from 1980 on, meaning that we would lose 30 years of data, in particular the period around the breakdown of the Bretton Woods system. When estimating long-run relations within a cointegration framework, the span of the data is more important than the frequency of the observations.

${ }^{13}$ The number of cashed checks is available since 1978, and the time series for debit card payments start with their introduction in 1987. Prior to these dates, we set the value of the respective series to zero. The value of cashed checks is available only since 1988, meaning that we would lose 10 years of data. From 1988 on, the number and the value of cashed checks are highly correlated, i.e., they seem to contain similar information. The value of credit card payments is also highly correlated with the number of cashed checks, and we decided not to include this series in the estimation. The number of cashed checks increased quite noticeably to reach a peak in 1988, after which they fell back to become almost negligible in the last couple of years. The value of debit card payments, in contrast, has exhibited a continuous increase since 1987.

${ }^{14}$ The exchange rate is quoted in terms of Swiss currency per unit of foreign currency so that an increase in the exchange rate denotes a depreciation of the Swiss franc.
} 
Table 1 Long-run relations based on cointegrating regression (DOLS) for groups of banknote denominations

\begin{tabular}{lccc}
\hline Variable & Large & Medium & Small \\
\hline Real GDP & $1.29^{* * *}$ & $0.33^{* * *}$ & $0.27^{* * *}$ \\
& {$[0.06]$} & {$[0.11]$} & {$[0.06]$} \\
Gov. bond yield & $-0.05^{* *}$ & 0.02 & $-0.03^{*}$ \\
Exchange rate & {$[0.02]$} & {$[0.04]$} & {$[0.02]$} \\
& $-0.65^{* * *}$ & -0.15 & 0.20 \\
Real debit card paym. & $-0.18]$ & {$[0.34]$} & {$[0.18]$} \\
No. of checks & {$[0.01]$} & $-0.03^{* * * *}$ & $-0.02^{* * *}$ \\
& $-0.01^{* *}$ & {$[0.01]$} & {$[0.01]$} \\
Adj. $R^{2}$ & {$[0.00]$} & $-0.03^{* * *}$ & $-0.02^{* * *}$ \\
Phillips-Ouliaris $\tau$-test & 0.99 & $0.01]$ & {$[0.00]$} \\
Hansen test & $-4.86^{*}$ & 0.82 & 0.87 \\
\hline
\end{tabular}

$*, * * * * *$ indicates significance at the $10 \%, 5 \%$, and $1 \%$ levels, respectively. A constant is included. Phillips-Ouliaris $\tau$-test is a cointegration test with null

hypothesis of no cointegration, while Hansen test is a cointegration test with null hypothesis of cointegration. The dependent variables are the real value in circulation of each group of denominations, deflated by the CPI; large denotes the sum of CHF 1000, 500, and 200, medium denotes the sum of CHF 100 and 50, while small denotes the sum of CHF 20,10, and 5. The sample period runs from 1950 to 2017. Data are from the Swiss National Bank, the BIS, and Historical Statistics of Switzerland Online (HSSO). The CHF 1000, CHF 500, CHF 100, and CHF 50 banknotes were first issued in 1907, the CHF 20 and CHF 5 bills were introduced in 1914. The issuance of the CHF 5 was suspended in 1958 after the introduction of the CHF 10 bill in 1956. The CHF 500 was replaced by the CHF 200 note in 1997

denominations with a value greater than one, indicating that for this group other motives of holding cash besides the transactions motive are important. The medium and small groups have similar income elasticities that are slightly lower than the famous 0.5 value of Baumol (1952) and Tobin (1956). Third, the effect of the interest rate is strongest for the largest denominations, which might be expected given the stronger role of portfolio considerations for these denominations. ${ }^{15}$ Nevertheless, also for the small denominations, opportunity costs, as measured by the government bond yield, are significant. Fourth, advances in payment technologies captured by debit card and check payments lead to some substitution away from cash, with the strongest effect for the medium denominations. This finding is in line with recent payment survey results for Switzerland (Swiss National Bank 2018), showing that debit cards are typically used for medium-sized purchases starting around CHF 50, while smaller amounts are primarily paid in cash. Fifth, the exchange rate is significant only for the largest denominations, indicating that foreign demand in the form of hoarding might be most important for this group. Overall, we conclude that portfolio considerations of domestic and foreign residents seem to play a role for the demand for banknotes, in particular for the large denominations. Finally, cointegration

\footnotetext{
${ }^{15}$ Stix (2013) presents survey evidence with many respondents reporting that they allocate part of their savings to cash.
}

tests are most decisive for the large denominations, where both tests indicate cointegration among the respective variables. For the medium and small denominations, the tests yield ambiguous results with the Hansen test indicating cointegration while the Phillips-Ouliaris $\tau$-test does not. In the following sections, we focus more specifically on non-transaction related demand and estimate hoarding shares for the different denominations using three different methods.

\section{Estimation based on the ratio of the number of banknotes}

Otani and Suzuki (2008) propose a simple method to estimate the share of banknotes not used for transactions based on the assumption that different denominations are utilized in similar proportions over time to effect payments. This assumption implies that different banknote denominations should grow proportionally over time such that their relative shares remain constant. Consequently, when large denominations are also demanded for hoarding purposes, the demand for large denominations would increase more than for small ones.

Of course, this simple reasoning rests on a number of assumptions. First, one has to identify a base year and a reference denomination relative to which the increase in hoarding demand is assessed. Second, inflation and increasing income may lead to a shift in transaction demand towards larger denominations. This effect becomes more significant the longer the sample period is to which the method is applied. Despite Switzerland being a country with one of the lowest inflation rates worldwide, the price level increased more than fourfold since 1950 and about threefold since 1970. Inflation would potentially lead to a higher demand for large-denomination banknotes, causing an overestimation of the hoarding share. The smaller denominations that we consider as the benchmark series, however, could also experience higher demand through the inflation effect as expenditures paid for by coins would increasingly be effected by banknotes; this would tend to mitigate the upward bias in the estimated hoarding share. Third, payment habits may change. Survey evidence (Deutsche Bundesbank 2015; Esselink and Hernandez 2017; Swiss National Bank 2018) as well as our estimates in the previous section indicate that with technological advances in payment systems cash tends to be replaced by credit or debit card payments, especially in larger transactions. This would counteract the potential effect of inflation on the use of different denominations and might lead us to underestimate the hoarding share.

For the choice of a suitable base year, we investigate the evolution of large denomination banknotes relative to smaller ones. A period of relative stability in the ratio of large to small denominations indicates that results would 
not be overly sensitive to the choice of a particular year. Notwithstanding the effects from inflation and financial innovation discussed above, periods in which the ratio between large and small denominations is low are indicative of low hoarding demand. Figure 1 shows that the respective ratio of CHF 1000 banknotes relative to CHF 100, 50, 20, and 10 banknotes has steadily risen since 1915, with noticeable increases during the banking crisis in 1931, during the breakdown of the Bretton Woods system and since the turn of the millennium. We choose the year 1950 as the base year for assessing the increase in hoarding demand because from 1950 on monthly data for each denomination in circulation became available, allowing us to calculate hoarding shares based on annual averages, whereas before 1950 only year-end data exist that might give rise to an overestimation of the hoarding share for the CHF 1000 banknote because of its pronounced seasonal peak in December. ${ }^{16}$ While the increase in 1931 is most likely due to a rise in the hoarding share that we would miss with 1950 as the base year, the effects of inflation and financial innovation become more relevant the further away the base year is.

The left-hand panel of Fig. 2 documents that the actual demand for CHF 1000 notes grew much more strongly than the imputed demand, using the growth rates of the CHF 50 and CHF 20 notes as a reference. ${ }^{17}$ As seen on the right-hand panel of Fig. 2, the resulting share of banknotes not used for transactions reached approximately $40 \%$ in 1970 and increased to approximately $70 \%$ at the end of the 1970s when the Bretton Woods system collapsed and the Swiss authorities introduced measures to limit the appreciation pressure on the Swiss franc. ${ }^{18}$ Around the turn of the millennium, the hoarding share further increased towards $80 \%$, which was likely motivated by the fear of a possible millennium bug in 2000, the burst of the dot-com bubble around the year 2000, the 9/11 terrorist attacks in 2001 , and the introduction of euro banknotes and coins in 2002. Finally, the financial and euro area crises led to another increase in the hoarding share, reaching 80 to $85 \%$ in 2017. This is much higher than the results by Otani and Suzuki (2008) who estimated a share of $40 \%$ in 2007 for the JPY 10,000 bill. ${ }^{19}$

\footnotetext{
${ }^{16}$ Results using 1970 as the base year are presented in the Appendix. While the hoarding shares evolve in a similar way, their levels are approximately 10 percentage points lower. In terms of denominations, the results do not change significantly for the CHF 1000 note, are noticeably lower for the CHF 500 note whereas - according to this calculation - the CHF 100 note would not have been hoarded.

${ }^{17}$ As the CHF 10 bill was only introduced in 1956, it cannot be used as a reference series with 1950 as the base year.

${ }^{18}$ To address strong capital inflows, capital controls such as negative interest rates on deposits of non-residents of up to $-10 \%$ per quarter and a ban on the acquisition of domestic financial assets by non-residents were imposed. Banknotes were used to bypass those measures. These measures were gradually phased out from 1979 onward; see Swiss National Bank (1982, pp. 290f) and Swiss National Bank (2007, pp. 195ff).

${ }^{19}$ Though the JPY 10,000 bill is the largest banknote in Japan, its value amounts to only around CHF 90 at the time of writing. As it is frequently used
}

For the CHF 500 banknote, Fig. 3 shows that the increase in hoarding up to 1975 was even more pronounced than for the CHF 1000 bill, reaching a peak of 72 to $75 \%$ in 1978 . Thereafter, the hoarding share steadily decreased until in 1997 the replacement of the CHF 500 by the CHF 200 banknote led to an almost immediate return of the CHF 500 notes in circulation to the SNB. ${ }^{20}$ As evidenced by the strong rise in hoarding shares in the 1960s and early 1970s, the CHF 1000 and CHF 500 bills seem to have been relatively close substitutes in terms of hoarding demand.

Figure 4 shows that for the CHF 100 note the imputed demand resulting from the CHF 50 and CHF 20 reference series was in fact larger than the actual demand from the late 1990s on when the CHF 200 bill was introduced. Moreover, demand for the CHF 100 note, similar to the CHF 500 note, seems to have been dampened by the introduction of wage accounts in Switzerland that took place in the 1960s and 1970s (see Krüger (2017) for a similar development in Germany). From the late 1960s to the early 1990s, the estimated hoarding share moves between 15 and 25\%. Following the introduction of the CHF 200 bill, estimated hoarding shares turn negative, indicating that the CHF 200 banknote is apparently a closer substitute to the CHF 100 than the previous CHF 500 banknote (see also Kohli 1988). The hoarding share picked up again from 2010 on during the euro area crisis, whereas the demand for the CHF 1000 banknote increased already in the early phase of the financial crisis, a pattern that conforms with the findings of the lifespan method presented in Section 4.

As the CHF 200 banknote was introduced only in 1997, we calculate the hoarding share with 1999 as the base year, giving the new bill 2 years to converge to a reference ratio relative to the smaller denominations. ${ }^{21}$ Figure 5 shows that, similar to the CHF 100 banknote, the latest increase in demand happened during the euro area crisis and not the earlier stages of the financial crisis. In 2017, the estimated hoarding share based on the CHF 20 and CHF 10 banknotes was approximately 40 to $50 \%$, about half the estimated hoarding share of the CHF 1000 banknote, which indicates that the CHF 200 note is not as close a substitute for the CHF 1000 bill as the CHF 500 .

Finally, we calculate the hoarding share for total banknotes (in value terms), adding up the estimates presented above and assuming that only banknotes of denomination CHF 100 and larger are hoarded while the

in day-to-day transactions and is also readily available at cash dispensers in Japan, the lower estimate is probably not surprising.

${ }^{20}$ The CHF 500 note, like the other banknotes of the 6th series, was officially recalled on 1 May 2000, meaning that it ceased to be legal tender. It can still be exchanged at full nominal value at the SNB until 30 April 2020. At the end of 2017, 200,000 CHF 500 notes (CHF 100 million in value) were still not returned.

${ }^{21}$ If adoption of the new denomination would take more than 2 years, we would overestimate the hoarding share for the CHF 200. 


\section{RATIO OF NUMBER OF BANKNOTES}

CHF 1000 banknote relative to other denomination

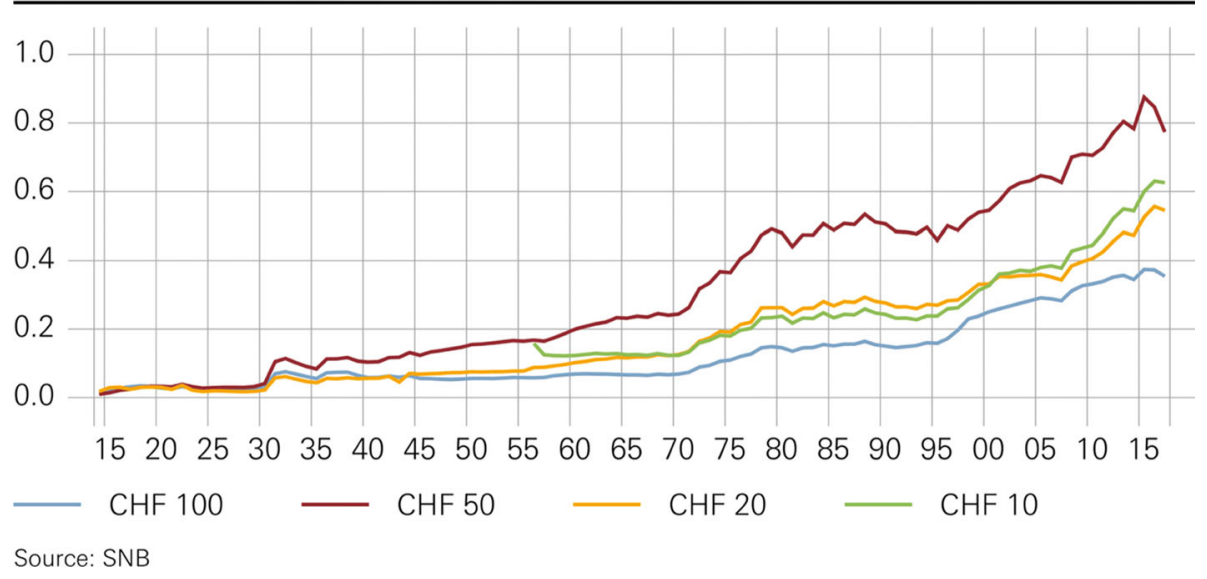

Fig. 1 Banknote ratios

smaller denominations are exclusively used for transactions. ${ }^{22}$ The resulting hoarding shares, shown in Fig. 6, rise steadily until the late 1970 s and then move sideways in a range between 40 and 50\% until the replacement of the CHF 500 by the new CHF 200 note in 1997. From this date on, we assume a hoarding share for the CHF 500 note of zero and use the estimated hoarding shares for the CHF 200 note from 1999 on (dashed lines in the graph). As is evident from Fig. 6, hoarding dropped following the introduction of the new note but re-attained its previous level after about 5 years and rose strongly during the financial crisis, reaching 50 to $60 \%$ of the value of total banknotes in circulation in 2017.

Overall, based on the method proposed by Otani and Suzuki (2008), we obtain a steep rise in the hoarding share during the 1960s and 1970s, a slight decline in the 1980s and 1990s and a further increase since the turn of the millennium, with an acceleration after the financial crisis. This general pattern is replicated by the method using data on the lifespan of different banknote denominations that we apply in the following section.

\section{Analysis based on the lifespan of banknotes}

Following Anderson (1977), we next estimate the hoarding share based on a comparison of the actual and theoretical lifespan of a banknote denomination. Of course, the lifespan of a banknote is determined by many factors such as the frequency with which it is used in transactions,

\footnotetext{
${ }^{22}$ This assumption is in line with the literature, see Bech et al. (2018).

Moreover, given that the CHF 1000 banknote accounts for more than $60 \%$ of the value of banknotes in circulation, hoarding of the smaller denominations would only have a limited influence on the estimated total hoarding share.
}

user habits (storage, folding, etc.), the technical durability of the banknotes, climate (humidity), and the central bank's policy when to remove a certain banknote. Here, we focus only on the impact on a banknote's lifespan of the intensity with which it is used, i.e., whether a banknote denomination is predominantly used for transactions or whether it is hoarded, assuming that all other determinants of the theoretical lifespan apply to the same degree to all banknote denominations.

The more a banknote denomination is used for hoarding the less it should wear out or return to the central bank and the longer its actual lifespan should be. The theoretical lifespan is defined as the time period a banknote would be in circulation if it is exclusively used for transactions.

We follow the literature and estimate an average lifespan for each banknote denomination. ${ }^{23}$ The average lifespan $L$ of a banknote denomination $i$ in period $t, L_{t}^{i}$, is calculated as the inverse of the replacement rate:

$$
L_{t}^{i}=\frac{B_{t}^{i}}{W_{t}^{i}},
$$

where $B_{t}^{i}$ is the number of banknotes of denomination $i$ that are in circulation in period $t$, and $W_{t}^{i}$ is the number of banknotes of denomination $i$ withdrawn as unfit for circulation in period $t$. Intuitively, the lifespan can be understood as the number of periods necessary to completely replace all banknotes of a specific denomination that are in circulation. However, this formula ignores the

\footnotetext{
${ }^{23}$ See, for example, Bartzsch et al. (2013b). While in principle the average lifespan of a banknote denomination can be calculated from the issuance and destruction dates for each serial number, we do not have these data available.
} 


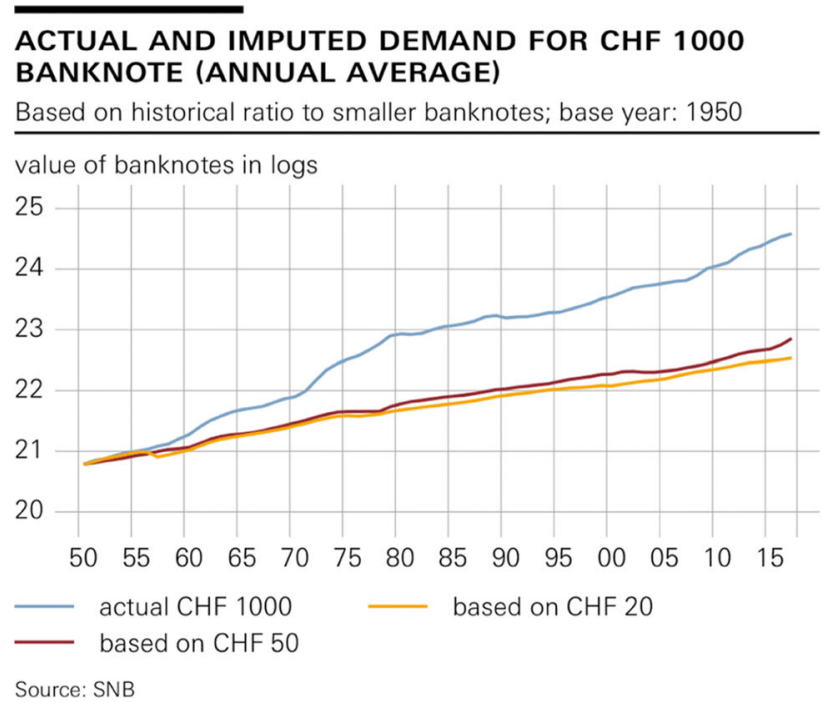

Fig. 2 Method based on ratios - results for CHF 1000 banknote

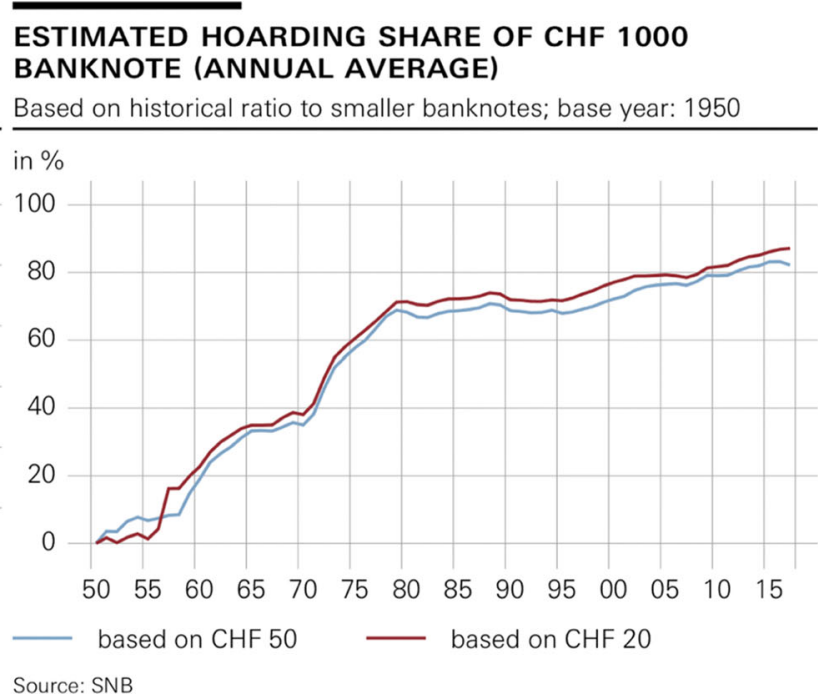

Source: SNB fact that the number of banknotes in circulation typically increases, due to economic growth or other reasons and the resulting estimated average lifespan is therefore biased upwards. As the number of newly issued banknotes typically exceeds the withdrawals, the following formula corrects for this bias: ${ }^{24}$

$$
L_{t}^{i}=\frac{B_{t}^{i}}{0.5\left(W_{t}^{i}+I_{t}^{i}\right)},
$$

where $I_{t}^{i}$ is the number of newly issued banknotes of denomination $i$ in period $t$.

To calculate the hoarding share, we define $\beta_{t}^{i}$ as the share of banknotes of denomination $i$ used for transactions,

$$
\beta_{t}^{i}=\frac{T_{t}^{i}}{B_{t}^{i}}
$$

where $\operatorname{Tr}_{t}^{i}$ is the (unobserved) number of banknotes of denomination $i$ used for transactions. Next, we rearrange and divide both sides by $0.5\left(W_{t}^{i}+I_{t}^{i}\right)$ to obtain:

$$
\frac{\operatorname{Tr}_{t}^{i}}{0.5\left(W_{t}^{i}+I_{t}^{i}\right)}=\beta_{t}^{i} \frac{B_{t}^{i}}{0.5\left(W_{t}^{i}+I_{t}^{i}\right)} .
$$

Note that the fraction on the right-hand side of Eq. (4) equals the definition of the estimated lifespan $L_{t}^{i}$ from Eq. (2), whereas the expression on the left-hand side is the

\footnotetext{
${ }^{24}$ See, for example, Feige (1989) and Bartzsch et al. (2013b). The formula also applies if the number of banknotes issued decreases, in which case $I_{t}^{i}$ would be negative. However, despite the spread of cashless payments media, only very few countries to date experience a decline in banknote demand in nominal terms.
}

estimator for the theoretical lifespan of a banknote, $L_{t}^{i, T}$, so that

$$
L_{t}^{i, T}=\beta_{t}^{i} L_{t}^{i}
$$

Therefore, the share of a specific denomination that is hoarded domestically or abroad, $\left(1-\beta_{t}^{i}\right)$, is equal to

$$
1-\beta_{t}^{i}=\frac{L_{t}^{i}-L_{t}^{i, T}}{L_{t}^{i}} .
$$

While we have data to calculate the effective lifespan $L_{t}^{i}$ for the different banknote denominations starting in 1970, we need to make an assumption to obtain an estimate of the theoretical lifespan for each denomination $L_{t}^{i, T}$. As in Andrist (1997), we compute the theoretical lifespan as the average of the effective lifespan of the smaller denominations, i.e., the CHF 10 and CHF 20 that we assume to be used predominantly for transaction purposes. ${ }^{25}$ To smooth the introduction of a new series, the central bank typically deviates from the usual patterns of issuance and withdrawals, thereby changing the estimated effective lifespan. As this change is not related to any change in user behavior, we abstract from those movements and replace the effective lifespan of a given denomination in those years by a linear interpolation using the closest lifespan data that do not seem to be affected by this policy change as a basis.

Overall, the resulting hoarding shares and their dynamics are similar to those obtained with the method based on the ratio of the number of banknotes. Results presented in

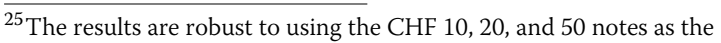
benchmark.
} 


\section{ACTUAL AND IMPUTED DEMAND FOR CHF 500 BANKNOTE (ANNUAL AVERAGE) \\ Based on historical ratio to smaller banknotes; base year: 1950}

value of banknotes in logs

23

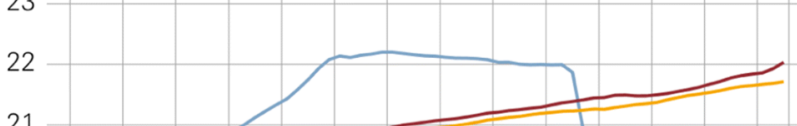

21

20

19

18

$$
\begin{aligned}
& 50 \quad 55 \quad 60 \quad 65 \quad 70 \quad 75 \\
& -\quad \text { actual CHF } 500 \\
& - \text { based on CHF } 50
\end{aligned}
$$

Source: SNB

Fig. 3 Method based on ratios - results for CHF 500 banknote

\section{ESTIMATED HOARDING SHARE OF CHF 500 BANKNOTE (ANNUAL AVERAGE)}

Based on historical ratio to smaller banknotes; base year: 1950

in \%

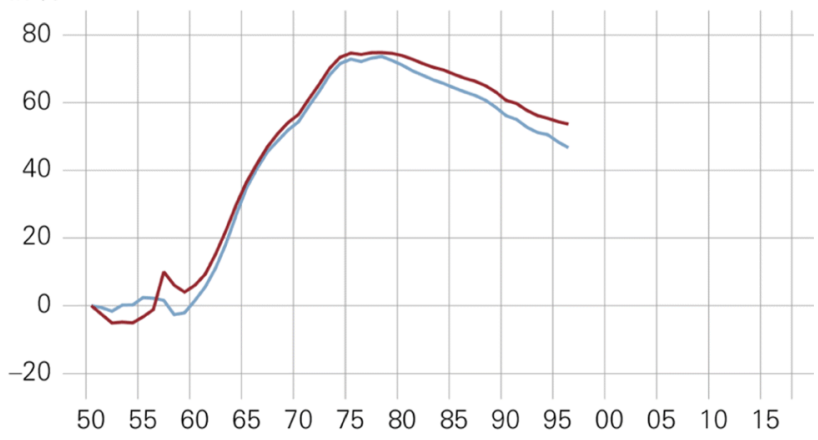

based on CHF 50

based on CHF 20

Source: SNB

Fig. 7 show that hoarding shares increased strongly during the break-up of the Bretton Woods system, around the turn of the millennium and in the wake of the recent financial and euro area crises. In contrast to the results in Section 3, hoarding shares were below $20 \%$ in the late 1980s. For the CHF 1000 banknote, the estimated hoarding share increased strongly around the turn of the millennium whereas it moved sideways with some spikes around the financial and euro area crises. The CHF 500 followed the same pattern as the CHF 1000 note until it was abolished, again demonstrating its close substitutability with the CHF 1000 note in terms of hoarding demand. The estimated hoarding share of the CHF 200 banknote peaked in 2001 before falling back and then increasing in two distinct stages during the financial crisis and the euro area crisis. ${ }^{26}$ The early phase of the financial crisis did not seem to have had an impact on the hoarding share of the CHF 100 note, which increased only later in the course of the euro area crisis. ${ }^{27}$ From the early 1980 s to the late 2000s, the hoarding share for the CHF 100 note oscillated between approximately 20 and 40\%. Interestingly, the introduction of negative interest rates in 2015 does not seem to have left an obvious mark on the hoarding share estimates. The estimated hoarding shares for the CHF 200 and CHF 100 bills decreased, whereas the hoarding share of the CHF 1000 note continued to fluctuate in its previous range. In 2017, hoarding shares were approximately

\footnotetext{
${ }^{26}$ The results from the method based on ratios presented in Section 3 only show an increase during the latter period.

${ }^{27}$ This conforms with the findings of the method based on ratios presented in Section 3.
}

$80 \%$ for the CHF $1000,50 \%$ for the CHF 200, and $15 \%$ for the CHF 100 banknotes.

Assuming that only denominations of CHF 100 and more are hoarded, the left-hand panel of Fig. 8 presents estimates of the hoarding share (in value terms) of total Swiss franc banknotes based on the previous results. The estimated hoarding share peaked at the end of the $1970 \mathrm{~s}$ at approximately 60\%, falling back to only 9\% in 1988 . Around the turn of the millennium, the overall hoarding share increased to more than 50\%, peaking at 69\% in 2014. In 2017 , the overall hoarding share stood at $60 \%$.

The right-hand panel of Fig. 8 shows a decomposition based on the estimated hoarding shares of total banknotes in circulation into those used for transaction and for hoarding purposes. Until the late 1990s, nominal hoarding demand moved sideways with some ups and downs. Since the turn of the millennium, hoarding demand exhibits a strong trend increase driving total demand, in particular since the recent financial crisis, up to about CHF 50 billion. In contrast, the estimated banknote demand for transactions was flat over the 1970s, after which it increased until the end of the 1980s. Subsequently, it moved sideways around a value of slightly more than CHF 20 billion up to at times CHF 30 billion. The amount hoarded exceeds the transaction amount since the beginning of the 2000 s.

\section{Analysis based on seasonal patterns}

Our final approach to estimate the share of hoarding or non-resident demand is based on a comparison of the seasonal pattern of banknotes to that of a benchmark series that exclusively relates to transactions. To calculate the 


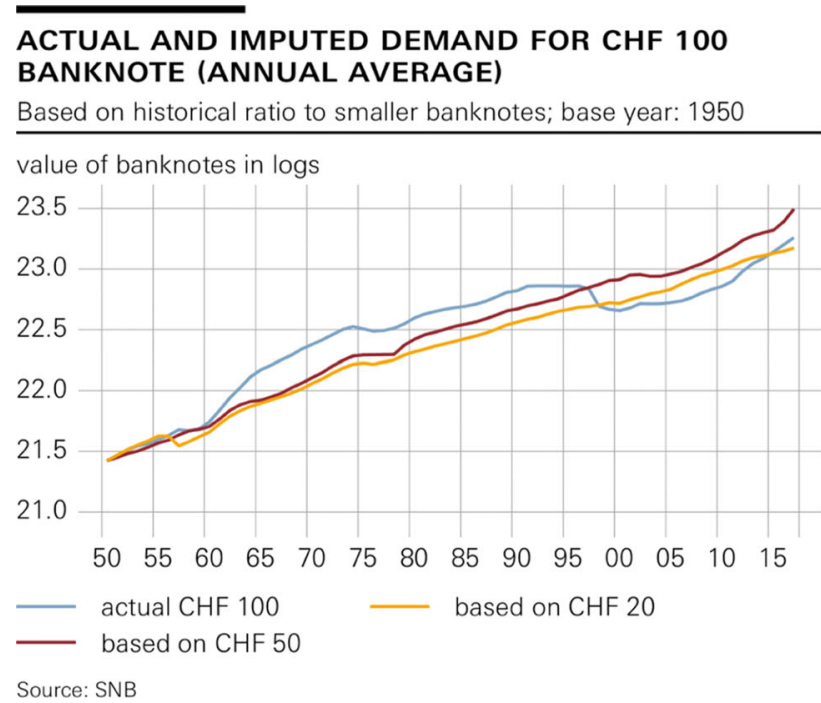

Fig. 4 Method based on ratios - results for CHF 100 banknote

\section{ESTIMATED HOARDING SHARE OF CHF 100 BANKNOTE (ANNUAL AVERAGE)}

Based on historical ratio to smaller banknotes; base year: 1950

in $\%$

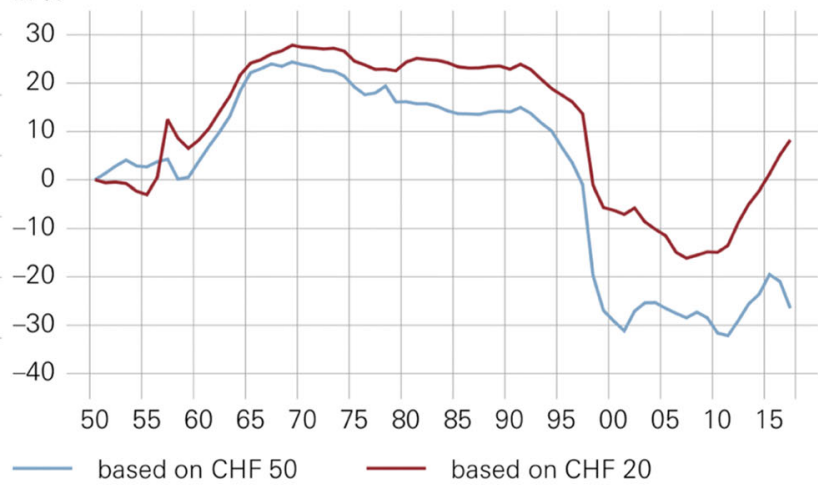

Source: SNB share of banknotes that is demanded for hoarding or by non-residents in year $t,\left(1-\beta_{t}\right)$, from the seasonal pattern, we use the following equation (for a derivation, see Assenmacher et al. 2018):

$$
1-\beta_{t}=1-\frac{S_{\max , t}-S_{\min , t}}{S_{\max , t}^{t r}-S_{\min , t}^{t r}},
$$

where $S_{\min , t}$ and $S_{\max , t}$ are the smallest and largest seasonal factors for the series of interest and $S_{\min , t}^{\mathrm{tr}}$ and $S_{\max , t}^{\mathrm{tr}}$ are those for a purely transaction-related series. This approach is based on the assumption that banknote demand for domestic transactions should be affected by events that occur regularly over the year such as Christmas shopping or summer holidays whereas banknote demand for hoarding purposes or demand by nonresidents is typically not subject to such seasonal variation. Therefore, the seasonal pattern of banknote demand should become less pronounced when the share of banknotes that are not used for transactions increases.

While $S_{t}$ can be calculated from the available data, $S_{t}^{\mathrm{tr}}$ is unknown and has to be approximated through a benchmark series that ideally should reflect only domestic transaction purposes. Possible choices are banknotes in circulation for a reference country that does not feature hoarding and demand by non-residents ${ }^{28}$ or a variable,

\footnotetext{
${ }^{28}$ A suitable reference should feature a qualitatively, but not quantitatively, similar seasonal pattern of banknote demand. In the past, Sweden was considered to be a reasonable reference country for Switzerland, but this does not seem to be true for more recent data. The seasonal factors for Sweden and Switzerland from 1980 to 2000 showed a pronounced seasonal peak in December and no visible peak in the summer months for both countries (Fischer et al. 2004, see p. 54). More recent data for Sweden, however, exhibit noticeable seasonal movements in the summer months that do not conform with the Swiss pattern anymore.
}

such as retail sales or private consumption expenditures, that should evolve in line with banknotes used in domestic transactions. ${ }^{29}$ As purely transaction-related benchmark series are difficult to find for Switzerland, we compare the seasonal factors across different banknote denominations, assuming that small denominations are mainly used for transactions, whereas large banknotes are more prone to hoarding demand. ${ }^{30}$

Assenmacher et al. (2018) obtain a hoarding share for the CHF 1000 banknote of between 40 and 70\% that increases over the last two decades with the seasonal method and monthly data for Swiss banknote denominations. While the literature usually compares the December seasonal peaks for all series, the result by Assenmacher et al. (2018) relies on the January to February seasonal range for the CHF 1000 note and the December to February seasonal range for the CHF 20 banknote as the reference series. The resulting estimates, however, are in line with our results based on the lifespan, as shown in Fig. 7. One problem in applying the seasonal method to the CHF 1000 banknote originates from the large, pronounced seasonal peak in December that exceeds the corresponding seasonal peaks for the smaller denominations and presumably occurs for other reasons than seasonal transactions demand, namely, year-end tax considerations related to

\footnotetext{
${ }^{29}$ In principle, domestic hoarding and non-resident demand could be separated if a reference country exists with a similar hoarding demand but no demand by non-residents or vice versa. Judson (2018) analyses domestic hoarding and foreign demand for the US with Canada as reference country; Bartzsch and Seitz (2016) estimate foreign demand for Germany employing France as reference country.

${ }^{30}$ For an overview of other alternatives such as coins or vault cash, see Bartzsch and Seitz (2016).
} 


\section{ACTUAL AND IMPUTED DEMAND FOR CHF 200 BANKNOTE (ANNUAL AVERAGE)}

Based on historical ratio to smaller banknotes; base year: 1999

value of banknotes in logs

23.2

23.0

22.8

22.6

22.4

22.2

22.0

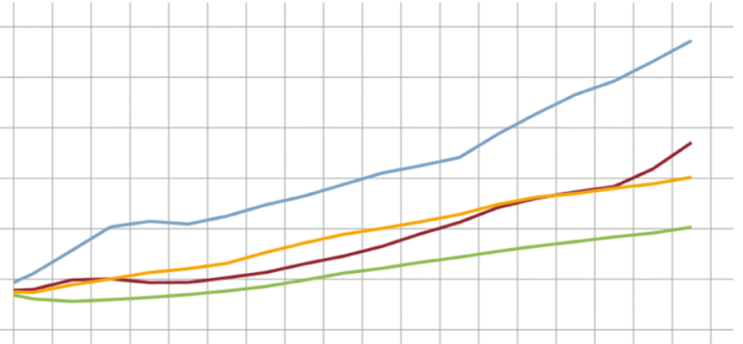

000102030405060708091011121314151617

- actual CHF 200
- based on CHF 50

- based on $\mathrm{CHF} 20$

based on $\mathrm{CHF} 10$

Source: SNB

Fig. 5 Method based on ratios - results for CHF 200 banknote

\section{ESTIMATED HOARDING SHARE OF CHF 200 BANKNOTE (ANNUAL AVERAGE)}

Based on historical ratio to smaller banknotes; base year: 1999

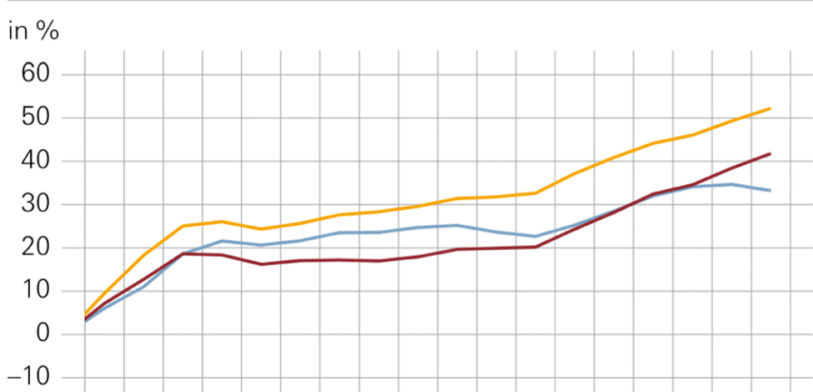

000102030405060708091011121314151617

- based on CHF 50

based on $\mathrm{CHF} 20$

Source: SNB the Swiss wealth tax. ${ }^{31}$ This motivates the aforementioned use of the January to February seasonal range for the CHF 1000 banknote. As bank statements issued for tax purposes show only the balance on December 31, giving an incentive to withdraw cash right before the end of December, end-of-month cash figures might be distorted for this reason. Most likely, the cash then is redeposited again until the end of January that features the second largest seasonal peak.

To avoid this tax-related end-of-month peaks, we reapply the seasonal method to time series that are based on other days of the month by making use of intramonthly data. In particular, we construct monthly time series for each denomination for the 10th and 20th day of the month. ${ }^{32}$ However, this approach did not help to dampen the seasonal variation in the CHF 1000 note relative to smaller denominations. Additionally, for days other than the last day of the month, the CHF 1000 series still shows the most pronounced seasonal pattern of all

\footnotetext{
${ }^{31}$ Effective taxable wealth can be reduced by withdrawing deposits in cash prior to the end of the year and re-depositing them at the beginning of the next. Such behavior would result in a pronounced seasonal peak in the demand for large banknotes in December. Being part of the taxable wealth, cash holdings have to be declared but are difficult to verify for the tax authorities. Ettlin and Fluri (1986) present evidence that tax effects indeed play a role, documenting a biannual regularity in the December peak, which they attribute to the biannual tax period that was common in many cantons until 2000. See also Lengwiler (2017).

${ }^{32}$ From 1950 to July 1979, we have data on the circulation of each denomination for the 7th, 15th, 23rd, and last day of a month. From August 1979 to April 2004, this information is available for the 10th, 20th, and last day of each month. From May 2004 to March 2008, weekly data are available for each Friday and the last day of a month. Based on the weekly data, we construct a time series for the 10th and 20th day of the month by choosing the closest day from the weekly data. From April 2008 on daily data are available. The results of this exercise are available from the authors upon request.
}

denominations. The maximum seasonal ranges for the 20th and the last day of a month are basically identical for the CHF 1000 and the CHF 20 banknotes. Using the 10th day leads to some reduction in the seasonal range of the CHF 1000 banknote, but it still remains markedly larger than the seasonal range of the CHF 20 banknote. ${ }^{33}$ We therefore did not further pursue the analysis of monthly seasonal patterns.

However, availability of higher frequency data enables us to use weekly or daily seasonal patterns for estimating the share of non-transactions related banknote holdings. Fischer et al. (2004) argue that the daily seasonal pattern should allow for an even cleaner identification of non-transaction-related demand, as hoarding could also be subject to intra-yearly seasonal variation caused, for instance, by seasonal patterns in tourism or preferred travel times of immigrants. The analysis of daily seasonality, however, is complicated as cycles of different periodicity overlay each other, further distorted by calendar effects that vary over the course of the years. Within a year, seasonality in banknote demand is driven predominantly by seasonal holidays, tax dates, and vacation periods that mostly occur in specific months of the year. Intra-monthly effects can be driven by pay days or tax dates.

Typically, banknote demand is high in the beginning and end of the month and lower in the middle. In addition, banknote demand displays an intra-weekly pattern with higher demand towards the weekend and low demand around the beginning of the week. The analysis of these

\footnotetext{
${ }^{33}$ This holds also true if the CHF 10 or the CHF 50 note is used instead of the CHF 20 banknote.
} 


\section{ESTIMATED HOARDING SHARE OF TOTAL CHF BANKNOTE (ANNUAL AVG., DISAGGREGATED APPR.)}

Based on historical ratio to smaller banknotes; base year: 1950

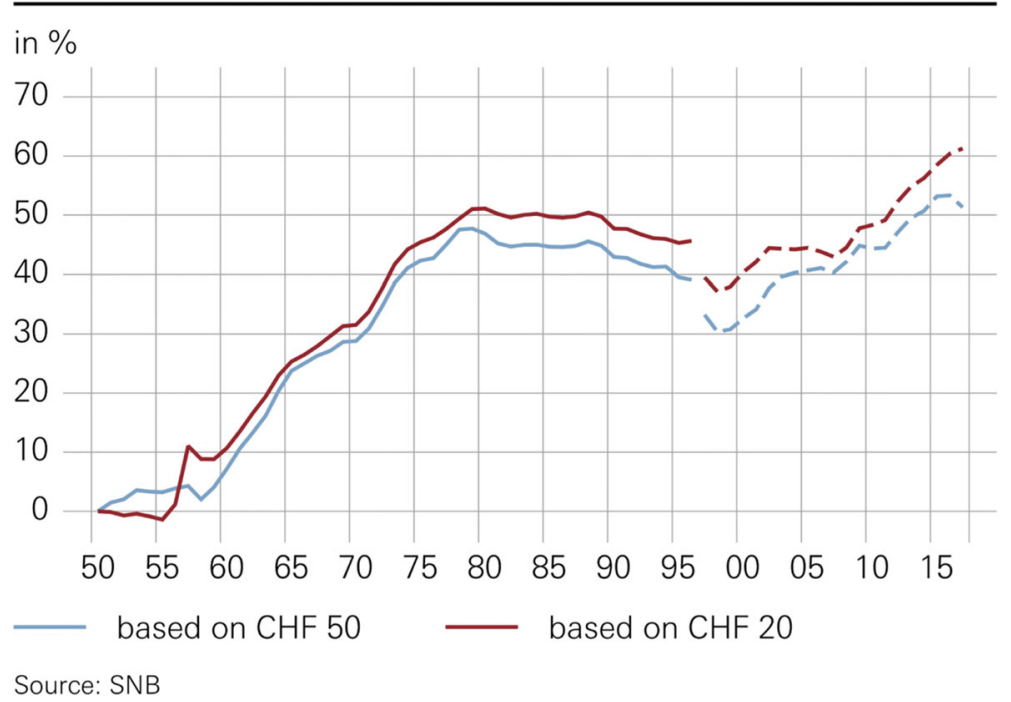

Fig. 6 Method based on ratios - results for total banknotes

various seasonal patterns is complicated by the fact that these cycles are not integer multiples of each other, as neither a month nor a year consist of an integer number of weeks. Additionally, these shifting cycles are further distorted by holidays that shift their timing in the year such as Easter or Pentecost. Seasonal adjustment of daily data needs to take account of all these effects.

Ollech (2018) recently suggested an STL-based approach to seasonally adjust daily data and to accommodate the aforementioned effects (see also Deutsche

\section{HOARDING SHARE OF SWISS BANKNOTE DENOMINATIONS}

Using banknote life span, theoretical life span: CHF 10 and 20

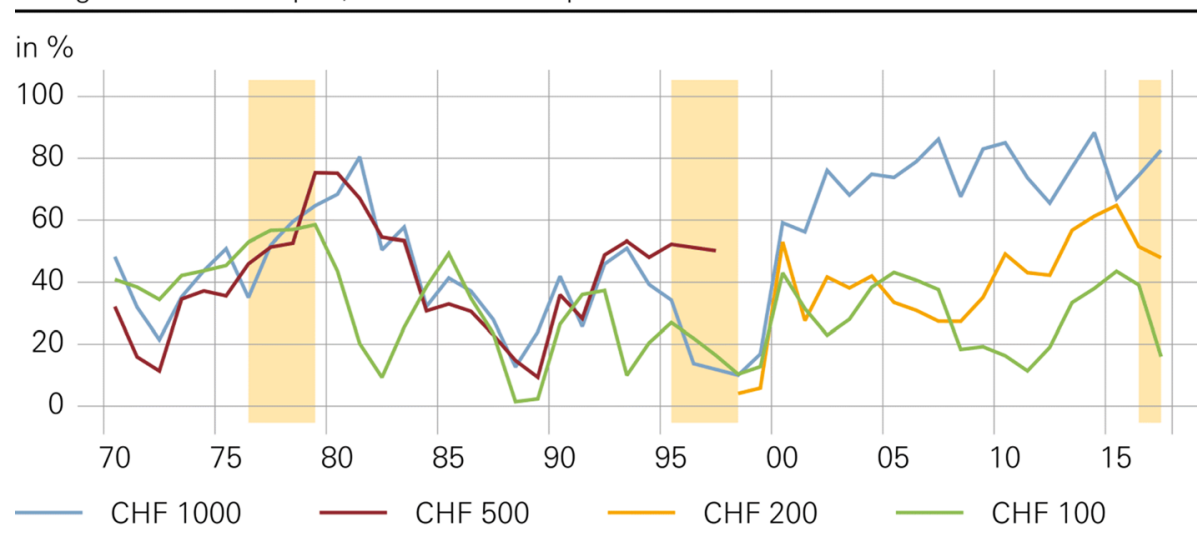

Source: SNB

Notes: Shaded areas indicate time periods in which new banknote series were brought into circulation. In Switzerland, the $6^{\text {th }}$ banknote series was introduced 1976-1979, 1995-1998 the denominations of the $8^{\text {th }}$ series were set into circulation, and in 2016

(until 2019) the introduction of the $9^{\text {th }}$ series began. The $7^{\text {th }}$ banknote series was a reserve series that was never put into circulation and ultimately destroyed.

Fig. 7 Method based on life span - results for large denominations 


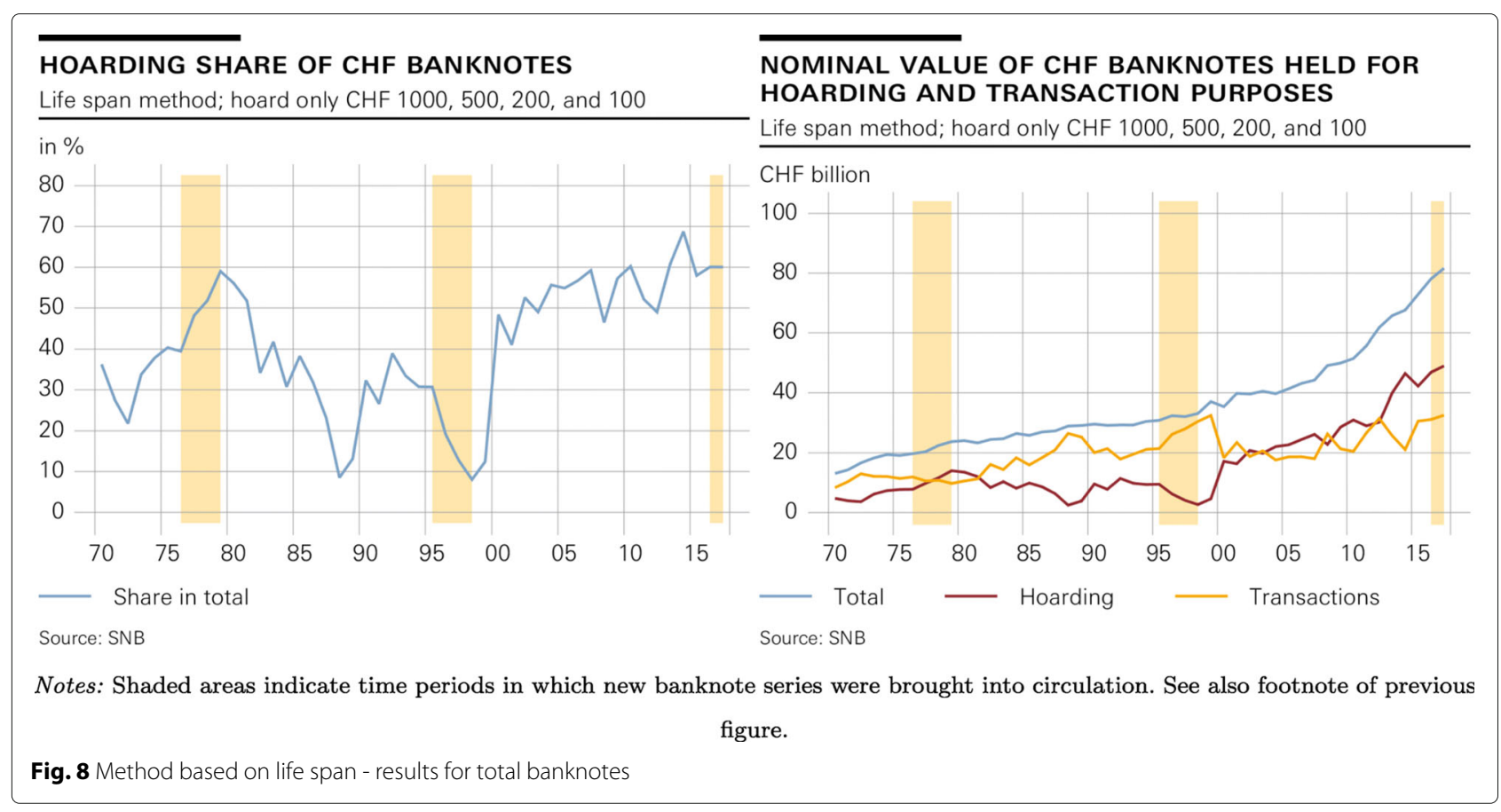

Bundesbank 2018). ${ }^{34}$ We apply his approach to daily time series of Swiss banknote denominations in circulation. The sample period runs from 1 November 2008 to 14 December $2018 .^{35}$ From the resulting seasonal factors, we compute the respective maximum seasonal ranges from which we derive hoarding share estimates using Eq. (7). The results are presented in Fig. 9. ${ }^{36}$ Overall, this approach leads to similar results as the method based on the lifespan for the same time period. The hoarding share of the CHF 1000 banknote hovers between 70 and $80 \%$. During the euro area crisis, the share increased from 72 to $80 \%$ but fell back afterwards. Subsequently, it increased again to reach a level of approximately $80 \%$ in 2017. The estimated hoarding share for the CHF 200 banknote is also similar to the share estimated using the lifespan. It increased during the euro area crisis from $25 \%$ to approximately $55 \%$ and then stayed in that range to reach $60 \%$ in 2017 . On average over the sample period, the estimated hoarding share for the CHF 1000 banknote is $73 \%$ and $48 \%$ for the CHF 200 banknote, which results in an overall hoarding share (in value terms) of $51 \% .{ }^{37}$

\footnotetext{
${ }^{34} \mathrm{He}$ combines an iterative seasonal adjustment routine based on STL with a RegARIMA model to estimate calendar and outlier effects. STL is a seasonal-trend decomposition based on Loess (locally estimated scatterplot) smoothing. See Cleveland et al. (1990).

${ }^{35}$ We exclude the early phase of the financial crisis in 2008 to avoid picking up volatility not related to seasonality.

${ }^{36}$ We show annual averages of the weekly estimates, as we want to abstract from the weekly volatility in the estimates.

${ }^{37}$ We take the hoarding share of the CHF 100 banknote to be zero, based on this approach.
}

\section{Summary and conclusion}

In this paper, we use different approaches to estimate the share of Swiss bank notes that are not used for transactions. As hoarding demand cannot be directly observed, it has to be estimated. Our main assumption is that large denomination banknotes are more likely to be hoarded than smaller ones. To make our results more robust, we compare the hoarding shares using different approaches and variables.

Our findings indicate a sizeable amount of hoarding (domestically or abroad), in particular for the two largest denominations, the CHF 1000 and the CHF 200 banknote. Different estimation methods give a quite consistent picture, in particular with respect to movements over time. The hoarding share generally increased around the breakup of the Bretton Woods system, was comparatively low in the mid-1990s, and has increased significantly since the turn of the millennium and the recent financial and euro area crises. The most notable difference between the denominations is that the CHF 1000 banknote increased already noticeably around the turn of the millennium, whereas the increase during the recent financial crisis was less pronounced; however, it occurred already in the early stage of the crisis. In contrast, the CHF 100 bill, which is also heavily used for transactions, saw a strong increase in its hoarding share only in the later stage of the euro area crisis. Taking up both patterns, the CHF 200 note increased both during the financial and the euro area crisis.

Comparing the level of the different estimation methods, Table 2 shows the hoarding estimates-both shares 


\section{HOARDING SHARE OF LARGE BANKNOTE DENOMINATIONS BASED ON DAILY DATA}

Seasonal method, annual avg., weekly max-min range, ref.: CHF 20

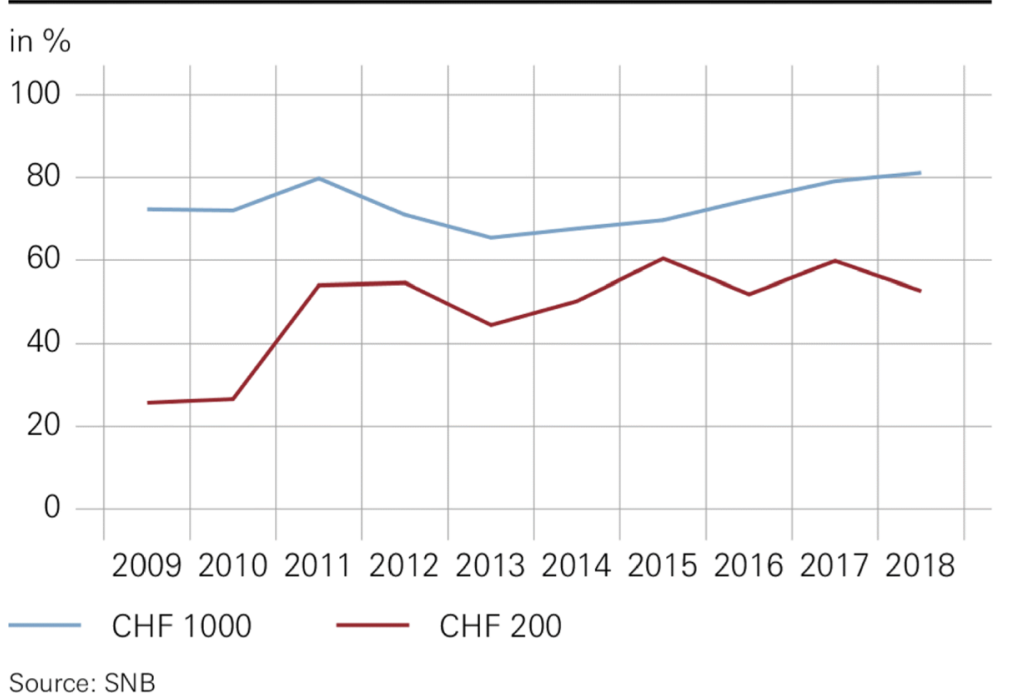

Fig. 9 Method based on seasonal patterns - results for large denominations

and amounts - for the different banknote denominations in Switzerland as well as for the total for the year 2017. The estimates for the total are strikingly similar: approximately $60 \%$ of all banknotes in value terms are not held for transaction purposes, corresponding to around CHF 45 billion. For the denominations, the estimates differ more, with a range of 79 to $87 \%$ for the CHF 1000 banknote, 42 to $60 \%$ for the CHF 200, and 8 to $16 \%$ for the CHF 100. Typically, those methods that yield higher hoarding estimates for the CHF 1000 lead to smaller numbers for the CHF 200 and CHF 100 notes and vice versa. As a result, the estimates for the total do not differ much. As the CHF 500 bill was abolished in 1997, we show estimates for 1996 that are also quite similar for the two methods for which we have data for that year: $51 \%$ or $54 \%$ (around CHF 2 billion).

In general, our estimated hoarding shares are comparable to the ones found in the literature for Switzerland for earlier time periods. Boeschoten (1992), for instance, finds a hoarding share of $45 \%$ for the Swiss franc in the 1980s, while Andrist (1997) obtains a value of $40 \%$ for 1995 based on the lifespan method. Moreover, the hoarding shares for the large Swiss franc denominations are in line with results found for other large denominations banknote internationally. Boeschoten and Fase (1992), for instance, obtain a hoarding share for the NLG 1000 banknote of between 60 and $80 \%$ in the late 1980s, depending on the method used. ${ }^{38}$ Bartzsch and Seitz (2016) estimate that approximately $75 \%$ of Deutsche Bundesbank's net issuance of the EUR 500 banknote was held outside the euro area in 2009. Porter and Judson (1996) estimate a hoarding share of 66 to $75 \%$ for the USD 100 bill in 1995, while more recently Judson (2018) obtains an estimate of 75\% for 2016.

In line with the situation in other currency areas, the demand for Swiss francs has increased in the last decade. As cash payments at the point-of-sale have decreased, the rise is due to other motives for holding cash, especially hoarding domestically and abroad as well as precautionary and crisis motives. This has to be taken into account when assessing the evolution of monetary aggregates and their macroeconomic impact. Moreover, it is especially important for cash logistics and the cash cycle to capture these non-transactions motives of cash demand adequately. We have defined "hoarding" very broadly. It is beyond the scope of the present paper to distinguish between foreign and domestic hoarding. Furthermore, we did not try to forecast the future demand for cash. Finally, we found that financial and economic crises have a significant positive influence on cash demand which might necessitate an increasing cash inventory of central banks. It would also be of interest to investigate the role of low and negative nominal interest rates on the hoarding behavior, especially if negative rates prevail over a long period of time. This is all left to future research.

${ }^{38}$ NLG 1000 corresponds to more than EUR 450 at the irrevocably fixed official exchange rate at the end of 1998. 
Table 2 Hoarding estimates for Swiss banknotes for 2017

\begin{tabular}{llllllc}
\hline Estimated hoarding for 2017 & \multicolumn{2}{l}{ Method based on ratios } & \multicolumn{2}{l}{ Lifespan method } & \multicolumn{2}{l}{ Seasonal method } \\
\hline Total & Share (in \%) & Amount (CHF billion) & Share (in \%) & Amount (CHF billion) & Share (in \%) & Amount (CHF billion) \\
CHF 1000 & 61 & 47 & 60 & 46 & 58 & 44 \\
CHF 500 & 87 & 41 & 83 & 39 & 79 & 38 \\
CHF 200 & 54 & 2 & 51 & 2 & - & - \\
CHF 100 & 42 & 5 & 48 & 5 & 60 & 7 \\
Th & 8 & 1 & 16 & 2 & - & -
\end{tabular}

The respective hoarding shares or amounts are estimates for the year 2017, except for the CHF 500 banknote, for which we show estimates for 1996. For the method based on ratios, we only show results based on the CHF 20 bill as reference 


\section{Appendix}

\section{NUMBER OF BANKNOTES IN CIRCULATION IN} SWITZERLAND

Total and denominations; annual average

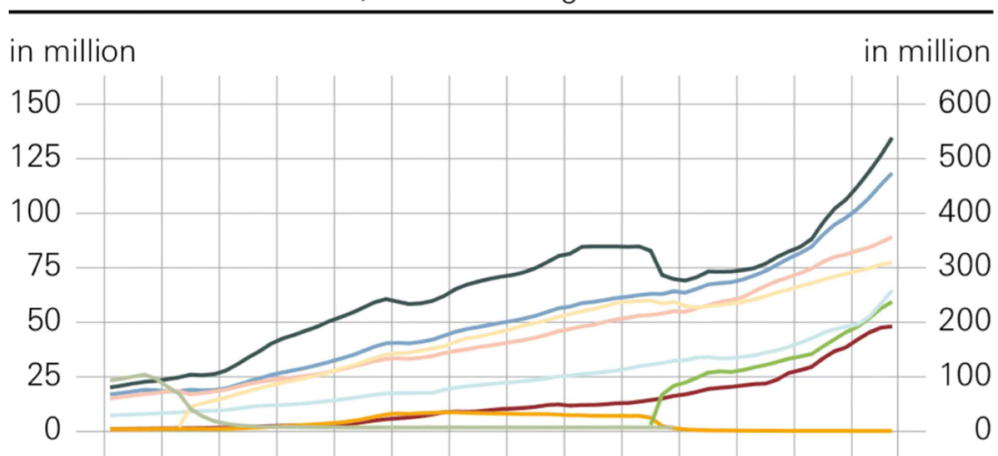

$\begin{array}{llllllllllllll}50 & 55 & 60 & 65 & 70 & 75 & 80 & 85 & 90 & 95 & 00 & 05 & 10 & 15\end{array}$
Total (right axis)
CHF 200
CHF 20
CHF 1000
CHF 100
CHF 10
CHF 500
CHF 50
CHF 5

SHARE OF BANKNOTE DENOMINATIONS IN TOTAL NUMBER OF BANKNOTES IN SWITZERLAND

Annual average

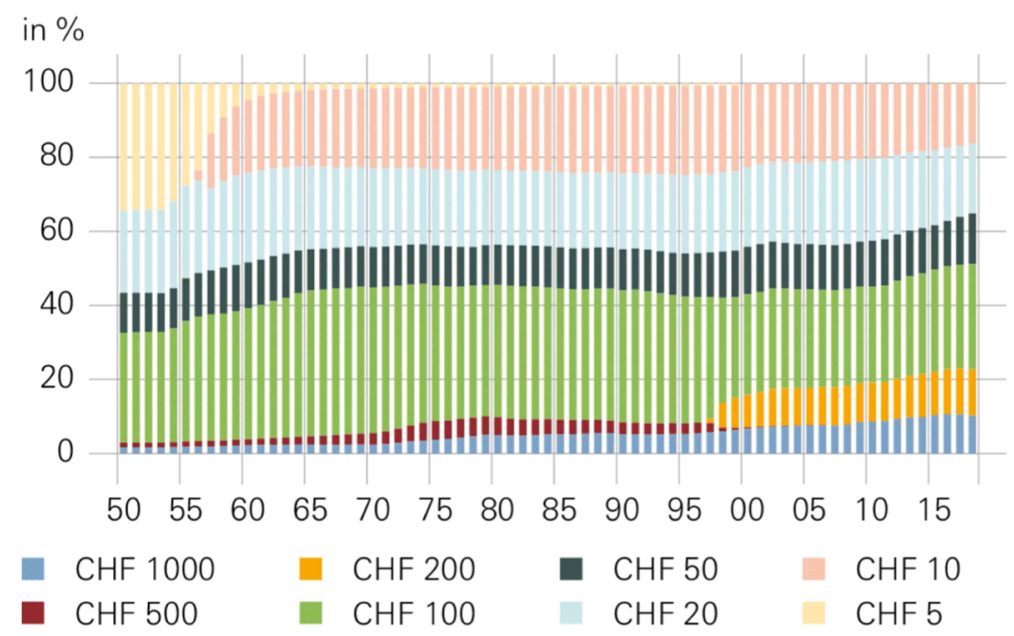

Fig.10 
NOMINAL VALUE OF BANKNOTES IN CIRCULATION IN SWITZERLAND

Total and denominations; annual average

CHF billion

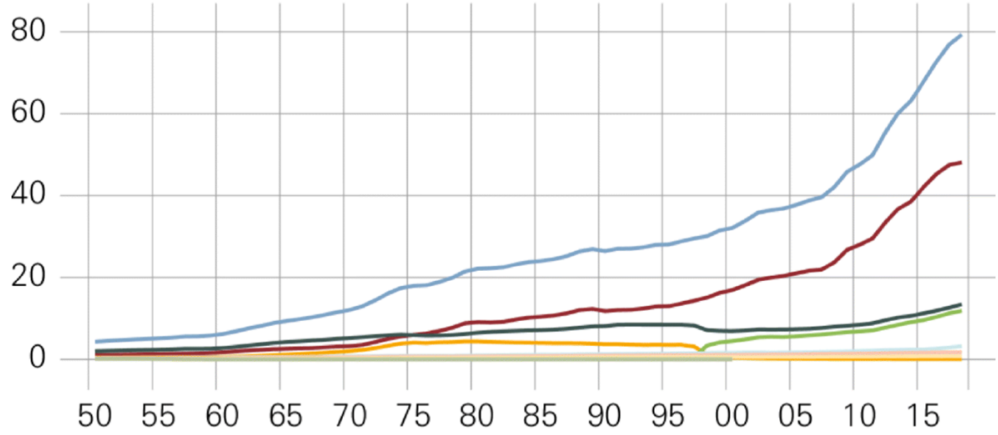
Total
CHF 200
CHF 20
CHF 1000
CHF 100
CHF 10
CHF 500
CHF 50
CHF 5

VALUE SHARE OF BANKNOTE DENOMINATIONS IN SWITZERLAND

Annual average

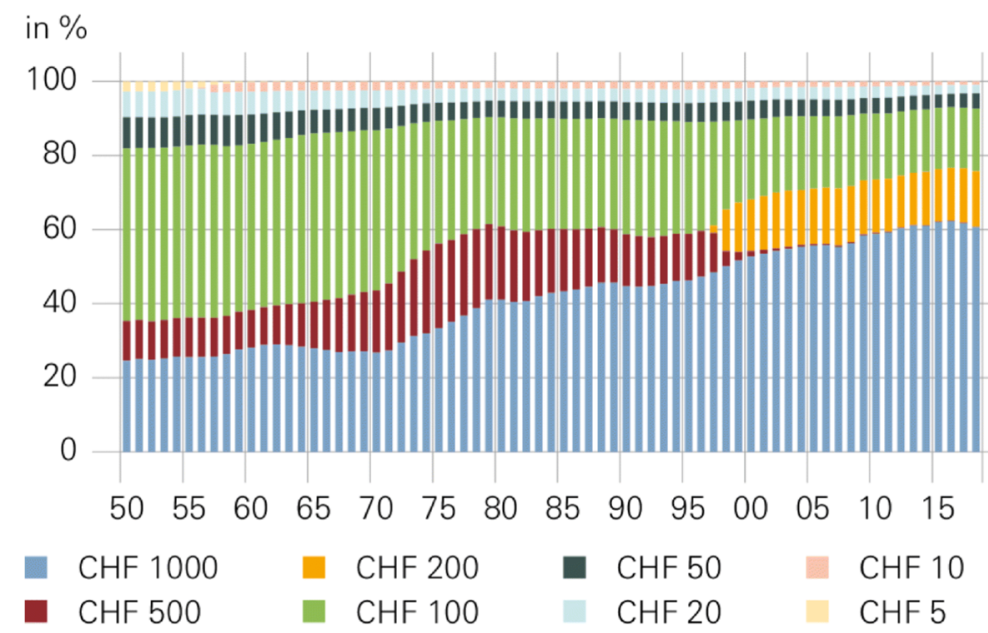

Fig.11 
ACTUAL AND IMPUTED DEMAND FOR CHF 1000 BANKNOTE (ANNUAL AVERAGE)

Based on historical ratio to smaller banknotes; base year: 1970

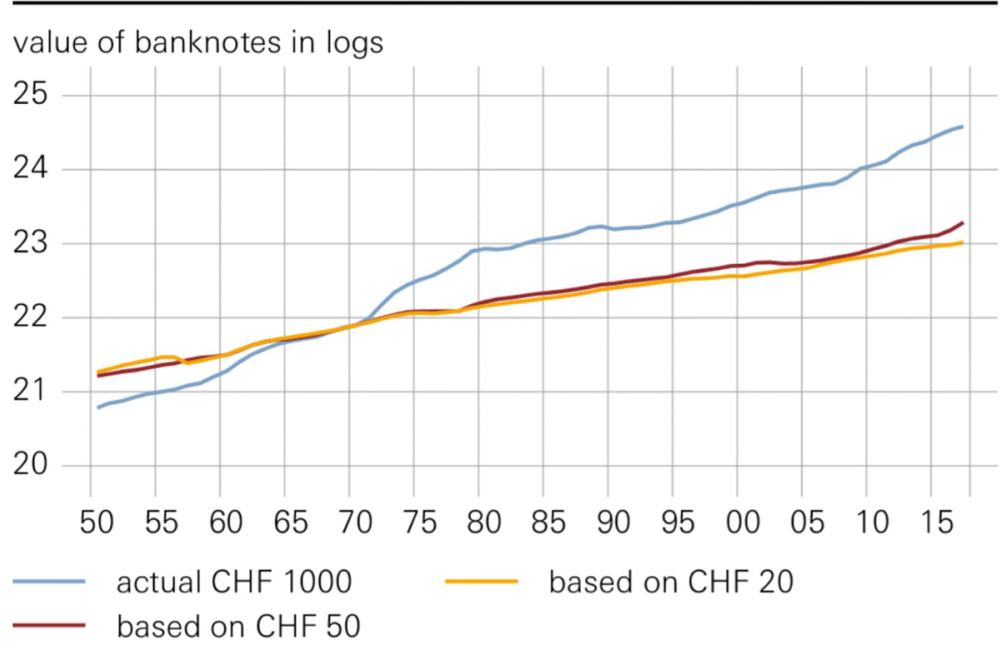

\section{ESTIMATED HOARDING SHARE OF CHF 1000}

BANKNOTE (ANNUAL AVERAGE)

Based on historical ratio to smaller banknotes; base year: 1970

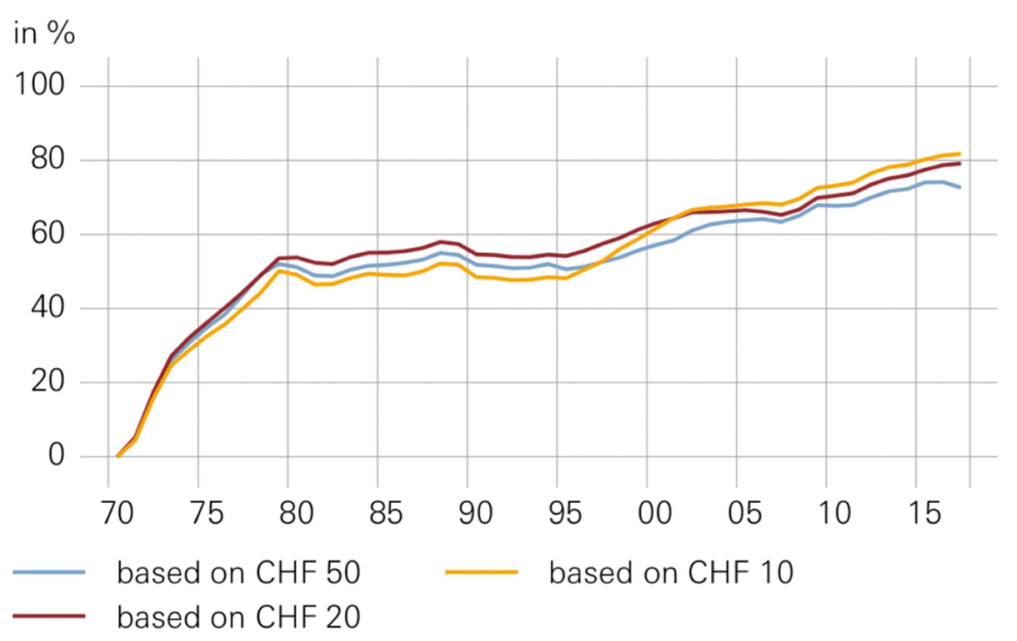

Fig.12 


\section{ACTUAL AND IMPUTED DEMAND FOR CHF 500} BANKNOTE (ANNUAL AVERAGE)

Based on historical ratio to smaller banknotes; base year: 1970

value of banknotes in logs

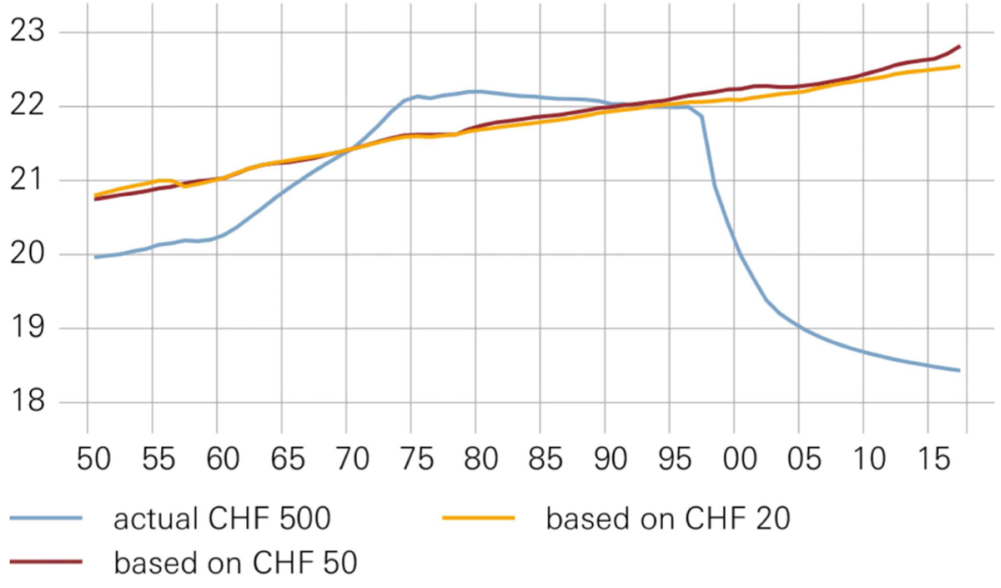

ESTIMATED HOARDING SHARE OF CHF 500 BANKNOTE (ANNUAL AVERAGE)

Based on historical ratio to smaller banknotes; base year: 1970

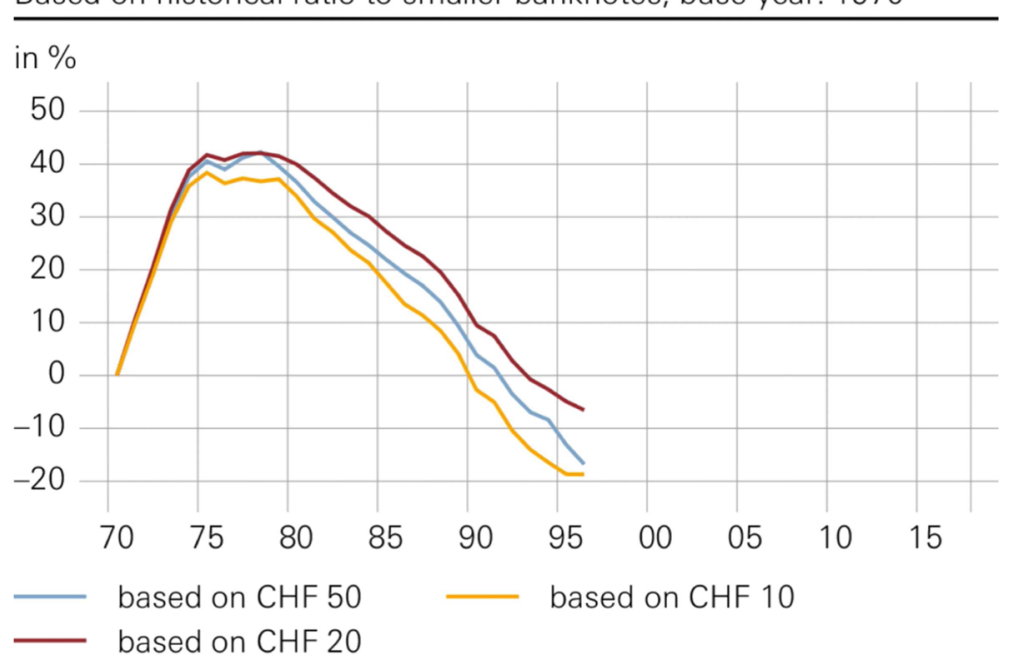

Fig.13 
ACTUAL AND IMPUTED DEMAND FOR CHF 100 BANKNOTE (ANNUAL AVERAGE)

Based on historical ratio to smaller banknotes; base year: 1970

value of banknotes in logs

24.0

23.5

23.0

22.5

22.0

21.5

21.0
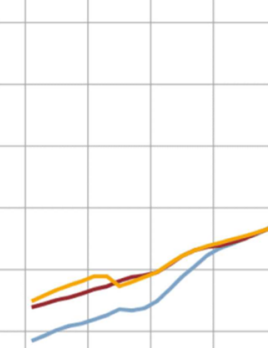

$\begin{array}{llllllllllllll}50 & 55 & 60 & 65 & 70 & 75 & 80 & 85 & 90 & 95 & 00 & 05 & 10 & 15\end{array}$

actual CHF 100

based on CHF 20

based on CHF 50

Source: SNB

ESTIMATED HOARDING SHARE OF CHF 100

BANKNOTE (ANNUAL AVERAGE)

Based on historical ratio to smaller banknotes; base year: 1970

in $\%$

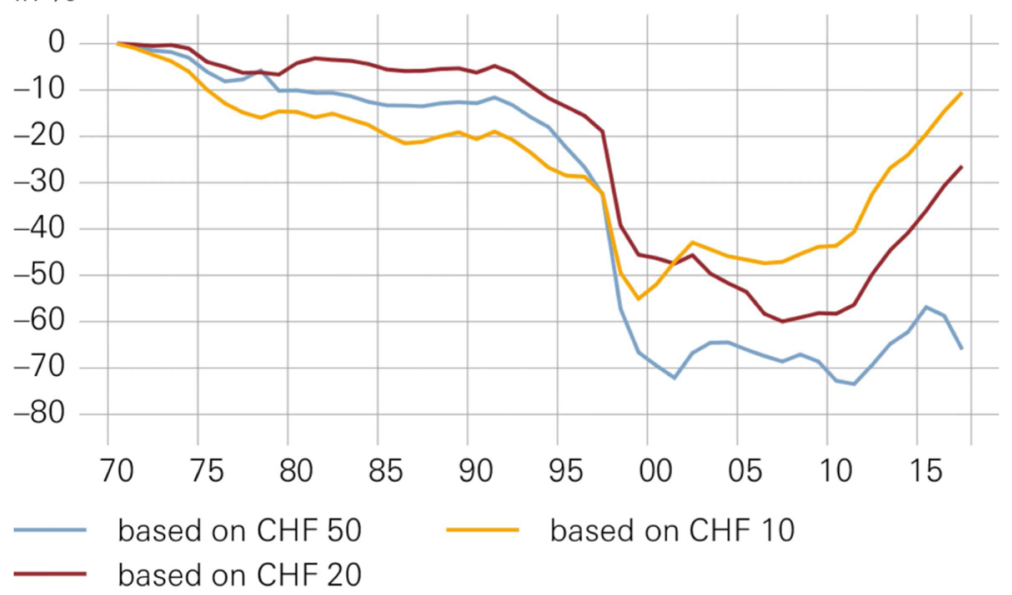


ESTIMATED HOARDING SHARE OF TOTAL CHF BANKNOTE (ANNUAL AVG., DISAGGREGATED APPR.)

Based on historical ratio to smaller banknotes; base year: 1970

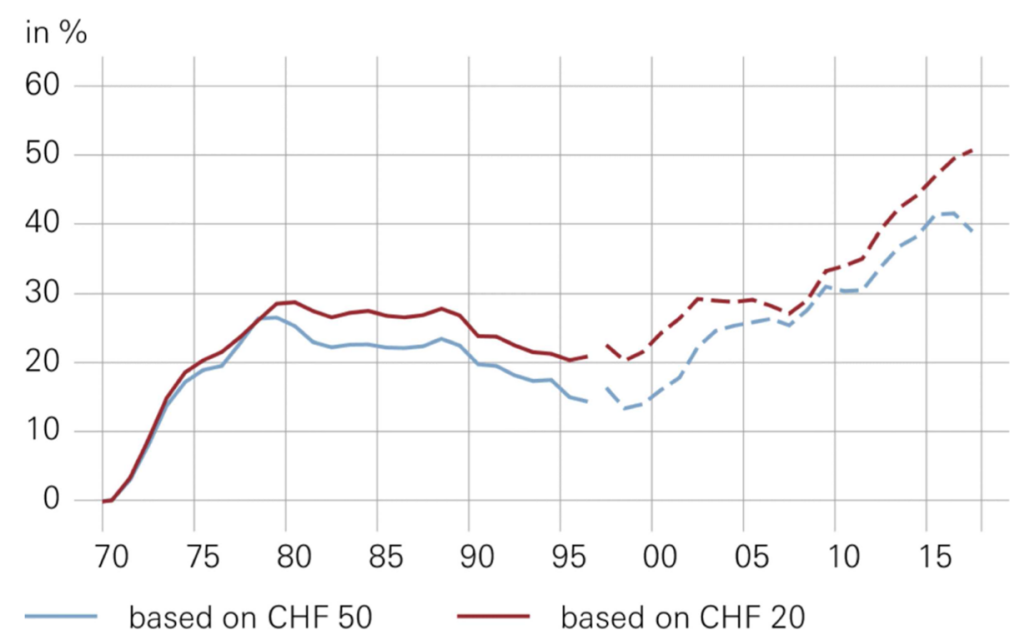

Fig.15 


\section{Abbreviations}

BIS: Bank for International Settlements; CHF: Swiss franc; CPI: Consumer price index; DOLS: Dynamic ordinary least squares; EUR: Euro; FMOLS: Fully modified ordinary least squares; GDP: Gross domestic product; HSSO: Historical Statistics of Switzerland Online; NLG: Dutch guilder; RegARIMA: Regression model with ARIMA (autoregressive integrated moving average) errors; SNB: Swiss National Bank; STL: Seasonal-trend decomposition based on Loess (locally estimated scatterplot) smoothing; US: United States; USD: US dollar; VECM: Vector error correction model

\section{Acknowledgements}

We thank Gregor Bäurle, Peter Eltschinger, Andreas Fischer, Alain Galli, Petra Gerlach, Beat Grossenbacher, David Hutmacher, Peter Kugler, Carlos Lenz, David Maurer, Simone Saupe and Cédric Tille for discussions and data provision, Daniel Ollech for making his code to seasonally adjust daily time series available to us, as well as seminar participants at the Bank for International Settlements, the Swiss National Bank, the Annual Congress 2018 of the Swiss Society of Economics and Statistics and the Understanding Cash Usage Seminar for comments. We also thank Tim Maurer for excellent research assistance. Comments from two anonymous referees greatly helped to improve the paper. All remaining errors are our own. The views expressed in this paper are those of the authors and not necessarily those of the European Central Bank or the Swiss National Bank.

\section{Authors' contributions}

All three authors have contributed to this paper on an equal footing. All authors have read and approved the final manuscript.

\section{Funding}

Not applicable.

\section{Availability of data and material}

The dataset used in the current study is available from the corresponding author upon reasonable request, subject to approval by the Swiss National Bank, as some of the banknote data are subject to confidentiality restrictions. Monthly data on banknote denominations are publicly available from August 1979 on via the SNB's data portal.

\section{Ethics approval and consent to participate} Not applicable.

\section{Consent for publication}

Not applicable.

\section{Competing interests}

The authors declare that they have no competing interests.

\section{Author details}

${ }^{1}$ European Central Bank, Sonnemannstr. 20,60314 Frankfurt am Main, Germany. ${ }^{2}$ Weiden Technical University of Applied Sciences, Hetzenrichter Weg 15, 92637 Weiden, Germany. ${ }^{3}$ Swiss National Bank, Börsenstrasse 15, 8022 Zürich, Switzerland.

\section{Received: 3 September 2018 Accepted: 12 August 2019}

Published online: 12 August 2019

\section{References}

Aksoy, Y., \& Piskorski, T. (2006). US domestic money, inflation and output. Journal of Monetary Economics, 53(2), 183-197.

Anderson, P.S. (1977). Currency in use and in hoards. New England Economic Review, Federal Reserve Bank of Boston (March/April), 21-30

Andrist, F. (1997). Das Geldnachfrageverhalten der Haushalte in der Schweiz (Money demand behavior of private households in Switzerland), volume 84 of Berner Beiträge zur Nationalökonomie. Bern, Switzerland: Verlag Paul Haupt.

Assenmacher, K., Seitz, F., Tenhofen, J. (2018). The use of large denomination banknotes in Switzerland. In Deutsche Bundesbank (Ed.), War on cash: Is there a future for cash?, International Cash Conference 2017, conference volume (pp. 148-199). Frankfurt am Main, Germany: Deutsche Bundesbank.

Bagnall, J., Bounie, D., Huynh, K.P., Kosse, A., Schmidt, T., Schuh, S., Stix, H. (2016). Consumer cash usage: A cross-country comparison with payment diary survey data. International Journal of Central Banking, 12(4), 1-61.
Banerjee, A., Dolado, J.., Hendry, D.F., Smith, G.W. (1986). Exploring equilibrium relationships in econometrics through static models: Some Monte Carlo evidence. Oxford Bulletin of Economics and Statistics, 48(3), 253-277.

Bartzsch, N., Rösl, G., Seitz, F. (2011a). Foreign demand for euro banknotes issued in Germany: Estimation using direct approaches. Deutsche Bundesbank Discussion Paper Series 1: Economic Studies, 20/2011.

Bartzsch, N., Rösl, G., Seitz, F. (2011 b). Foreign demand for euro banknotes issued in Germany: Estimation using indirect approaches. Deutsche Bundesbank Discussion Paper Series 1: Economic Studies, 21/2011.

Bartzsch, N., Rösl, G., Seitz, F. (2013a). Currency movements within and outside a currency union: The case of Germany and the euro area, The Quarterly Review of Economics and Finance, 53(4), 393-401.

Bartzsch, N., Rösl, G., Seitz, F. (2013b). Estimating the foreign circulation of banknotes. Economics Letters, 119(2), 165-167.

Bartzsch, N., \& Seitz, F. (2016). Cash holdings in Germany and the demand for "German" banknotes: What role is there for cashless payments? In J. Górka (Ed.), Transforming payment systems in Europe. (pp. 148 -199). Basingstoke, England: Palgrave Macmillan.

Bartzsch, N., \& Uhl, M. (2018). Domestic and foreign demand for euro banknotes issued in Germany. In Deutsche Bundesbank (Ed.), War on cash: Is there a future for cash? International Cash Conference 2017 conference volume (pp. 251-287). Frankfurt am Main, Germany: Deutsche Bundesbank.

Baumol, W.J. (1952). The transactions demand for cash: An inventory theoretic approach. The Quarterly Journal of Economics, 66(4), 545-556.

Bech, M., Faruqui, U., Ougaard, F., Picillo, C. (2018). Payments are a-changin' but cash still rules. BIS Quarterly Review (March), 67-80.

Boeschoten, W.C. (1992). Currency Use and Payment Patterns. Dordrecht, The Netherlands: Kluwer Academic Publishers.

Boeschoten, W.C., \& Fase, M.M. (1992). The demand for large bank notes, Journal of Money, Credit and Banking, 24(3), 319-337.

Campos, J., Ericsson, N.R., Hendry, D.F. (1996). Cointegration tests in the presence of structural breaks. Journal of Econometrics, 70(1), 187-220.

Cleveland, R.B., Cleveland, W.S., McRae, J.E., Terpenning, I. (1990). STL: A seasonal-trend decomposition procedure based on Loess. Journal of Official Statistics, 6(1), 3-73.

Deutsche Bundesbank (2015). Zahlungsverhalten in Deutschland 2014: Dritte Studie über die Verwendung von Bargeld und unbaren Zahlungsinstrumenten. Frankfurt am Main, Germany: Deutsche Bundesbank.

Deutsche Bundesbank (2018). The demand for euro banknotes at the Bundesbank. Deutsche Bundesbank Monthly Report (March), 37-51.

Engle, R.F., \& Granger, C.W. (1987). Cointegration and error correction: Representation, estimation and testing. Econometrica, 55(2), 251-276.

Esselink, H., \& Hernandez, L. (2017). The use of cash by households in the euro area. European Central Bank, Occasional Paper Series, 201.

Ettlin, F., \& Fluri, R. (1986). Der Einfluss der Steuerveranlagung auf den Notenumlauf - Identifikation und Quantifizierung (The influence of tax assessment on banknotes in circulation - identification and quantification). SNB Quarterly Bulletin, 3, 194-199.

Feige, E.L. (1989). Currency velocity and cash payments in the U.S. economy: The currency enigma. Munich Personal RePEC Archive.

Fischer, B., Köhler, P., Seitz, F. (2004). The demand for euro area currencies: past, present and future: European Central Bank, Working Paper Series, 330.

Flannigan, G, \& Parsons, S. (2018). High-denomination banknotes in circulation: A cross-country analysis. Reserve Bank of Australia Bulletin (March), 14-30.

Jobst, C., \& Stix, H. (2017). Doomed to disappear? The surprising return of cash across time and across countries. CEPR Discussion Paper, 12327.

Judson, R. (2018). The death of cash? Not so fast: Demand for U.S. currency at home and abroad, 1990-2016. In Deutsche Bundesbank (Ed.), War on cash: Is there a future for cash?, International Cash Conference 2017, conference volume (pp. 200-248). Frankfurt am Main, Germany: Deutsche Bundesbank.

Knell, M., \& Stix, H. (2005). The income elasticity of money demand: A meta-analysis of empirical results. Journal of Economic Surveys, 19(3), 513-533.

Kohli, U. (1988). A note on banknote characteristics and the demand for currency by denomination. Journal of Banking and Finance, 12(3), 389-399.

Krüger, M. (2017). The introduction of cashless wage payments and the spread of branch banking in post-war Germany. Financial History Review, 24(2), 185-207.

Lengwiler, Y. (2017). Wozu 1000er-Noten? ("What for CHF 1000 notes?") In Swiss National Bank (Ed.), Monetary Economic Issues Today, Festschrift in honour of Ernst Baltensperger (pp. 149-159). Zürich, Switzerland: Orell Füssli. 
Ollech, D. (2018). Seasonal adjustment of daily time series. Deutsche Bundesbank Discussion Paper, 41/2018.

Otani, A., \& Suzuki, T. (2008). Background to the high level of banknotes in circulation and demand deposits. Bank of Japan Review, 2008-E-5, 1-8.

Porter, R.D. (1993). Estimates of foreign holdings of US currency: An approach based on relative cross-country seasonal variations. Washington D.C.: Board of Governors of the Federal Reserve System.

Porter, R.D., \& Judson, R.A. (1996). The location of U.S. currency: How much is abroad? Federal Reserve Bulletin (October), 883-903.

Rogoff, K.S. (2016). The curse of cash. Princeton, USA: Princeton University Press.

Stix, H. (2013). Why do people save in cash? Distrust, memories of banking crises, weak institutions and dollarization. Journal of Banking and Finance, 37(11), 4087-4106.

Sveriges Riksbank (2018). The Riksbank's e-krona project. Report 2 (October).

Swiss National Bank (1982). 75 Jahre Schweizerische Nationalbank-Die Zeit von 1957 bis 1982. Zürich, Switzerland: SNB.

Swiss National Bank (2007). Die Schweizerische Nationalbank 1907-2007. Zürich, Switzerland: SNB.

Swiss National Bank (2018). Survey on payment methods 2017. Zürich, Switzerland: SNB.

Tobin, J. (1956). The interest-elasticity of transactions demand for cash. The Review of Economics and Statistics, 38(3), 241-247.

\section{Publisher's Note}

Springer Nature remains neutral with regard to jurisdictional claims in published maps and institutional affiliations.

\section{Submit your manuscript to a SpringerOpen ${ }^{\circ}$ journal and benefit from:}

- Convenient online submission

Rigorous peer review

- Open access: articles freely available online

- High visibility within the field

- Retaining the copyright to your article

Submit your next manuscript at $>$ springeropen.com 